\title{
Geohazards Monitoring and Assessment Using Multi-Source Earth Observation Techniques
}

\author{
Joaquim J. Sousa ${ }^{1,2, *(\mathbb{D}, \text { Guang Liu }}{ }^{3}$, Jinghui Fan ${ }^{4}$, Zbigniew Perski ${ }^{5}$, Stefan Steger ${ }^{6}$, Shibiao Bai ${ }^{7}{ }^{\circ}$, \\ Lianhuan Wei ${ }^{8}$, Stefano Salvi ${ }^{9}{ }^{\circ}$, Qun Wang ${ }^{10}$, Jienan Tu ${ }^{4}$, Liqiang Tong ${ }^{4}$, Peter Mayrhofer ${ }^{6}$, \\ Ruth Sonnenschein $\left.{ }^{6}{ }^{(}\right)$, Shanjun Liu ${ }^{8}$, Yachun Mao ${ }^{8}$, Cristiano Tolomei ${ }^{9}{ }^{\circ}$, Christian Bignami ${ }^{9}$, \\ Simone Atzori ${ }^{9}$, Giuseppe Pezzo ${ }^{9}$, Lixin $\mathrm{Wu}^{11}$, Shiyong Yan ${ }^{12}$ and Emanuel Peres ${ }^{1,2}$ (D)
}

check for

updates

Citation: Sousa, J.J.; Liu, G.; Fan, J.; Perski, Z.; Steger, S.; Bai, S.; Wei, L.;

Salvi, S.; Wang, Q.; Tu, J.; et al.

Geohazards Monitoring and

Assessment Using Multi-Source Earth Observation Techniques. Remote Sens. 2021, 13, 4269. https://doi.org/ $10.3390 /$ rs13214269

Academic Editors: Zhong Lu and Oriol Monserrat

Received: 30 July 2021

Accepted: 20 October 2021

Published: 24 October 202

Publisher's Note: MDPI stays neutra with regard to jurisdictional claims in published maps and institutional affiliations.

Copyright: (C) 2021 by the authors Licensee MDPI, Basel, Switzerland. This article is an open access article distributed under the terms and conditions of the Creative Commons Attribution (CC BY) license (https:// creativecommons.org/licenses/by/ $4.0 /)$.
1 Engineering Department, School of Science and Technology, University of Trás-os-Montes e Alto Douro, 5000-801 Vila Real, Portugal; eperes@utad.pt

2 Centre for Robotics in Industry and Intelligent Systems (CRIIS), INESC Technology and Science, 4200-465 Porto, Portugal

3 Key Laboratory of Digital Earth Science, Aerospace Information Research Institute, Chinese Academy of Sciences, Beijing 100094, China; liuguang@radi.ac.cn

4 China Aero Geophysical Survey and Remote Sensing Center for Natural Resources, Beijing 100083, China; jh15fan@agrs.cn (J.F.); tujienan@mail.cgs.gov.cn (J.T.); tongliqiang@mail.cgs.gov.cn (L.T.)

5 Carpathian Branch, Polish Geological Institute-National Research Institute, 31-560 Cracow, Poland; zper@pgi.gov.pl

6 Institute for Earth Observation, Eurac Research, 39100 Bolzano, Italy; Stefan.Steger@eurac.edu (S.S.); petmayr@gmail.com (P.M.); ruth.sonnenschein@eurac.edu (R.S.)

7 College of Marine Science and Engineering, Nanjing Normal University, Nanjing 210046, China; Shibiaobai@njnu.edu.cn

8 School of Resources and Civil Engineering, Northeastern University, Shenyang 110819, China; weilianhuan@mail.neu.edu.cn (L.W.); liushanjun@mail.neu.edu.cn (S.L.); maoyachun@mail.neu.edu.cn (Y.M.)

9 Istituto Nazionale di Geofisica e Vulcanologia, National Earthquake Observatory, Via di Vigna Murata 605, 00143 Rome, Italy; stefano.salvi@ingv.it (S.S.); cristiano.tolomei@ingv.it (C.T.); christian.bignami@ingv.it (C.B.); simone.atzori@ingv.it (S.A.); guseppe.pezzo@ingv.it (G.P.)

10 China Highway Engineering Consultants Corporation, Beijing 100081, China; wangqun3@cccltd.cn

11 School of Geosciences and Info-Physics, Central South University, Changsha 410083, China; wulx66@csu.edu.cn

12 School of Environment Science and Spatial Informatics, China University of Mining and Technology, Xuzhou 221116, China; yanshiyong@cumt.edu.cn

* Correspondence: jjsousa@utad.pt; Tel.: +351933254140

Abstract: Geological disasters are responsible for the loss of human lives and for significant economic and financial damage every year. Considering that these disasters may occur anywhere-both in remote and/or in highly populated areas-and anytime, continuously monitoring areas known to be more prone to geohazards can help to determine preventive or alert actions to safeguard human life, property and businesses. Remote sensing technology-especially satellite-based-can be of help due to its high spatial and temporal coverage. Indeed, data acquired from the most recent satellite missions is considered suitable for a detailed reconstruction of past events but also to continuously monitor sensitive areas on the lookout for potential geohazards. This work aims to apply different techniques and methods for extensive exploitation and analysis of remote sensing data, with special emphasis given to landslide hazard, risk management and disaster prevention. Multi-temporal SAR (Synthetic Aperture Radar) interferometry, SAR tomography, high-resolution image matching and data modelling are used to map out landslides and other geohazards and to also monitor possible hazardous geological activity, addressing different study areas: (i) surface deformation of mountain slopes and glaciers; (ii) land surface displacement; and (iii) subsidence, landslides and ground fissure. Results from both the processing and analysis of a dataset of earth observation (EO) multi-source data support the conclusion that geohazards can be identified, studied and monitored in an effective way using new techniques applied to multi-source EO data. As future work, the aim is threefold: extend this study to sensitive areas located in different countries; monitor structures that have strategic, cultural and/or economical relevance; and resort to artificial intelligence (AI) techniques to be able to 
analyse the huge amount of data generated by satellite missions and extract useful information in due course.

Keywords: geohazards; landslide detection; landslide inventory; remote sensing; InSAR; MT-InSAR; offset tracking; change vector analysis; land cover change

\section{Introduction}

China is a vast and very heterogeneous territory in which the occurrence of geohazards is permanent. In fact, some of the world's most severe geohazards occur in this territory every year, causing significant economic losses and several fatalities. This paper presents the most relevant results achieved with a Dragon 4 program project named "Landslide Identification, Movement Monitoring And Risk Assessment Using Advanced Earth Observation Techniques" (reference Dragon 4 ID 32365. Further information about this project can be found on the Dragoon 4 Cooperation Programme webpage (https: / / earth.esa.int/documents /163802/2550004/32365_PROJECT_SUMMARY.pdf [accessed on 29 July 2021])). Ground deformations are frequent, and they are widely distributed over the Chinese territory [1-7], causing geohazards in mountainous regions and urban areas. Therefore, continuous monitoring of different types of moving events and the early detection of potential threats are key to try to safeguard populations and minimize economic losses. Traditional approaches of ground deformation monitoring are based on ground measurement techniques, such as levelling and Global Navigation Satellite System (GNSS) monitoring [8,9] and on discrete measurements [10,11]. Satellite-based remote sensing approaches would allow researchers to obtain the overall deformation distribution over large geographic areas. Over the past two decades, several methods based on Synthetic Aperture Radar (SAR) data have been developed and were proven effective in determining deformations of the Earth's crust. This led to the development of numerous SAR missions, originating the current availability of large amounts of SAR imagery. Multi-temporal interferometry (MT-InSAR) appears as the unique remote sensing technology able to monitor deformation from space with millimetre accuracy [12-15]. Indeed, MT-InSAR approach, mainly including Persistent Scatter InSAR (PS-InSAR), Small BAselines Sub-set InSAR (SBAS-InSAR) and Distributed Scatter InSAR (DS-InSAR), have been widely used when extracting the earth's surface deformation [16-18] and present an efficient approach for various geohazards, with emphasis to landslide hazard, risk management and disaster prevention [4-6,19-26]. MT-InSAR was the main technology used to monitor glaciers, landslides deformations and subsidence in different areas and contexts within this Dragon 4 project's scope.

This work brings significant advancements concerning the exploitation of EO data, resulting in a deeper understanding of the associations between multiple geohazards and their causing factors. While high-resolution SAR images enabled the detailed surface movement characterization of several mountain glaciers, eight new potential landslide sites and one new potentially dangerous rock site were dully identified, on top of the demonstrated ability for detecting and monitoring landslides in mountainous areas using novel optical satellite sensors. Moreover, although previous investigations on geohazards in open pit mining areas were only done on limited points or in small areas with on-site monitoring devices—such as electronic total stations, GNSS, borehole inclinometers and micro-seismic devices-this paper presents the research of spatial distribution and temporal variations of geohazards over large areas. Figure 1 depicts all of the areas studied within the Dragon 4 (ID 32365) project, whose results are presented and discussed in this paper. 


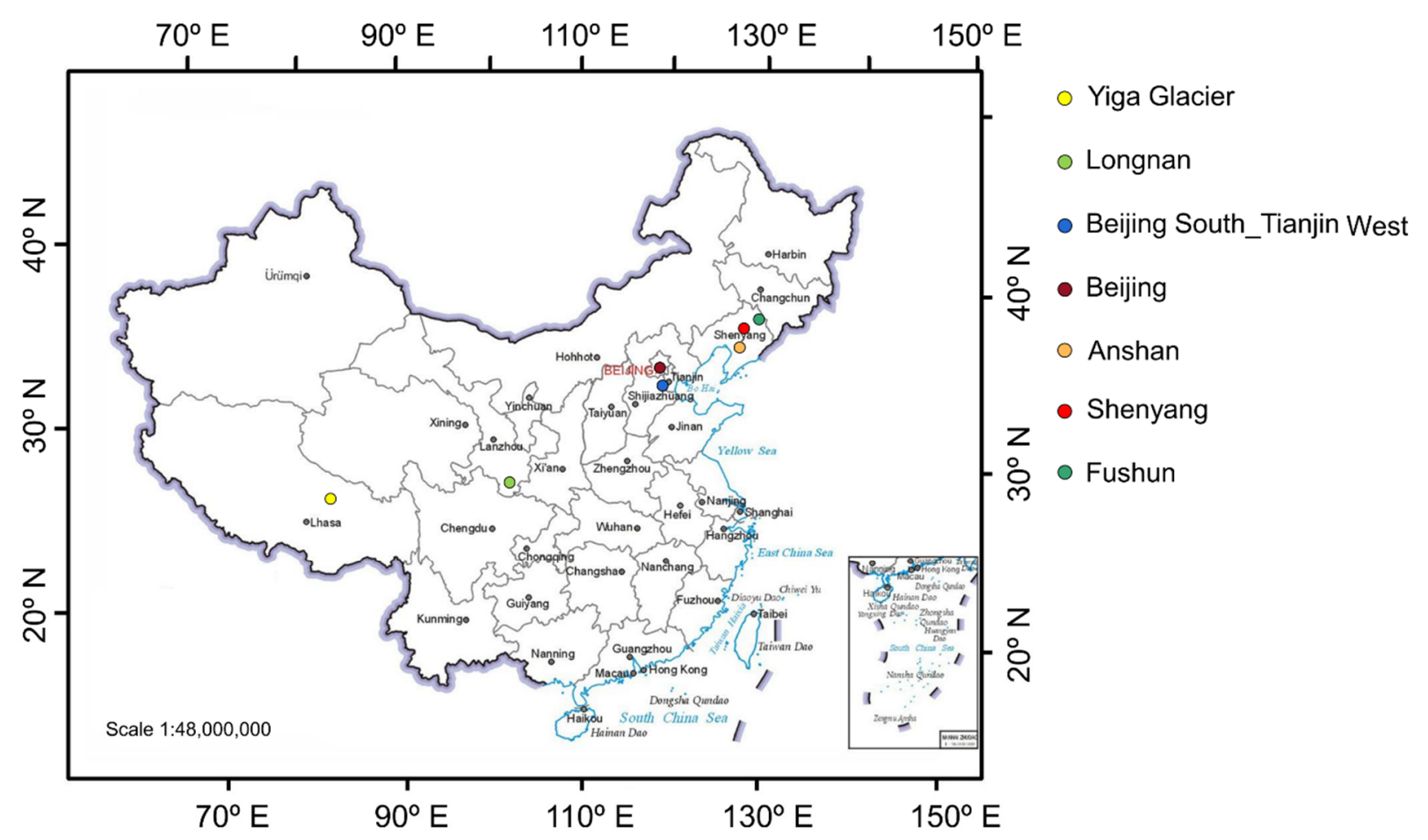

Figure 1. Location of the areas of interest used in the Dragon 4 project.

\subsection{Glaciers}

Glacial movement is influenced by the mass balance, temperature and hydraulic characteristics of glaciers $[27,28]$. Over long periods of time, glacial velocity depends on both terrain and climate [28]. However, mountain glaciers may also pose serious risks to the safety of downstream human settlements due to the possibility of floods caused by the outburst of glacial lakes, as well as debris' flows caused by glacial movement [29-31]. In Chinese Tibet, alone, there have been known glacial lake outbursts since the 1930s, which have resulted in tremendous losses of life, property and infrastructure in the adjacent downstream areas [32]. The monitoring of glacial movements, especially those connected to lakes, is of the utmost importance. Remote locations and difficult environments in which many mountain glaciers are found make remote sensing technology the proper tool to monitor glaciers' surface movements regularly and across large spatial scales [32-38]. As an important component of remote sensing technology, several techniques and methods for monitoring glacial velocity based on SAR data were developed. Gray et al. presented a SAR image registration method that can extract displacements in the azimuth and range directions of glaciers [39]. Multi-aperture interferometry (MAI), proposed by Bechor et al. [40], utilizes the phase information of SAR images to provide a way to extract highaccuracy displacements in azimuth direction. The accuracy of the offset tracking technique is generally 1/10- to 1/30-pixel size, and it is generally more robust. Moreover, SAR images' resolution is now possible at a scale of $<1 \mathrm{~m}$. Thus, the offset tracking technique allows for sub-decimetre accuracy [41]. In this paper, velocity results based on SAR images are validated using a 3D laser scanner: a non-contact measurement system [42]. By scanning the study area multiple times and comparing the spatial distribution of resulting point clouds, the area's deformation can be measured [43], allowing for complementary validation of the measurements made via SAR data.

\subsection{Landslides and Subsidence}

Landslide hazard and land subsidence can be better characterised using SAR-based techniques and methods. Beijing and its south region were investigated using Sentinel-1 Terrain Observation by Progressive Scans (TOPS) Interferometric Wide Swath (IW) full- 
resolution and the GF-3 (GaoFen Satellite 3) imagery. Details about different studies related to landslides that were carried out in different environments and contexts can be found in Guang Liu et al. [43]. SAR technology is also particularly useful to monitor deformations induced by underground exploitation. China's northeast is a traditional heavy industrial region and has played an important role in the country's economic development $[44,45]$. The study area used in this work covers $3000 \mathrm{~km}^{2}$ and is located in a quadrangular area linking four traditional heavy industrial cities-Benxi, Anshan, Shenyang and Fushun (BASF) - in Liaoning Province. After decades of exploitation, this region's resources are depleted, leaving various geological and environmental problems behind. Benxi and Anshan's main industry was iron (mining industry), with various open-pit mines. The main issues are landslides in mining pits and dump sites, subsidence, ground fissures, structural degradation of buildings, tailings ponds' dams break, etc. Shenyang is the provincial capital of Liaoning, which is suffering from ground subsidence caused by intensive construction of subways and ground water extraction. Fushun is a city with a coalmining history going back more than 100 years. It has the largest openpit mine in Asia. Landslides, building inclination, land subsidence and fissures due to anthropogenic activities have become primary geological threats to the local population and their properties. In many cases, the geological problems in this region are actually a complication of multiple geological disasters. Therefore, continuous and precise monitoring of the spatial and temporal variations of multiple geohazards in the BASF area is important for early warning and risk assessment. As such, in this paper, we present the study of multiple geohazards over the traditional heavy industrial base in the BASF region, using multi-temporal SAR interferometry. Instead of only monitoring a single geohazard, this work also set out to reveal the spatio-temporal process and complicated associations of multiple geohazards and eventually analyses their main causing factors (e.g., mining excavation, mining bursting, underground construction, groundwater extraction and earthquake) or possible interactions via data modelling and assimilation technique.

\subsection{Spatio-Temporal Identification of Landslides}

A reliable spatio-temporal identification of both historical and recent landslides is paramount to the understanding of current and future landslide dynamics. Landslide inventory maps are the foundation of landslide susceptibility and hazard assessment. Furthermore, they are also key to evaluate the adverse consequences of landslides and associated risks. Most available landslide inventories are based on labour-intensive and time-consuming field surveys, the analysis of historical documents, technical reports or on a tedious visual interpretation of EO data, such as aerial and satellite images or derivatives of high-resolution digital terrain models [46-49]. Particularly since the early 1970s, approaches based on EO data are constantly gaining popularity in the field of landslide recognition. EO-based landslide recognition techniques generally aim to identify and delineate past or current slope instabilities by exploiting the wealth of information inherent in remote sensing data [50]. The increasing availability of high temporal resolution satellite imagery rendered the application of change detection techniques feasible to map landslide events. Such approaches compare environmental conditions over time (e.g., pre-event vs. post-event conditions), and in case of optical imagery, they are frequently based on the assumption that a landslide event is accompanied by detectable vegetation disturbances [51-53]. The range of published research mainly includes approaches founded on optical imagery, high resolution digital terrain models or data from SAR. As for mapping units, both pixel-based and object-oriented approaches can be employed to delineate landslide features $[47,54,55]$.

The automated identification and mapping of slope instabilities has become a hot research topic with a growing availability of computational resources, significant progress in the development of automated image processing chains and due to an increasing availability of free satellite imagery. Within this context, the start of the Copernicus Sentinel-2 mission in 2015 opened up new possibilities in applying change detection approaches using freely available high-resolution optical data. Open-source landslide recognition approaches 
are now feasible at a higher detail compared to previous attempts based on freely available data from ASTER or Landsat. Still, applications of very high-resolution commercial satellite imagery $(<2 \mathrm{~m})$ with a nominal resolution can be expected to out-perform Sentinel-2-based approaches regarding the detection of small landslides [54,55]. Besides spatial resolution, temporal aspects also play a role on the detectability of slope instabilities in optical satellite imagery, since landslides may be best identifiable on cloud-free days with minimal shadow and in periods when landslide features and land cover patterns of the surroundings produce a sharp radiometric contrast [55]. Distinct contrast changes over time may be of particular relevance for the success of change detection approaches.

\subsection{Main Contributions}

This paper provides readers with significant contributions in remote sensing, resorting to multi-source EO techniques based on MT-InSAR and optical imagery in three application areas: (i) glaciers monitoring, especially their velocity and respective influencing factors; (ii) detection and monitoring of subsidence and landslides deformations; and (iii) understanding associations between geohazards and their causing factors. With regard to (i), not only can glacial surface velocity be successfully estimated, but the relation between it and temperature, rainfall and snowfall days is also analysed. As for (ii), large-scale land subsidence monitoring and landslide hazard and risk assessment proved to be accurate using both InSAR data and optical-based methods using freely available Sentinel data. However, in some contexts where human intervention in the landscape is higher, a specialist would probably be needed to complement the automatic assessment. Lastly, with regard to (iii), proving that continuous and precise monitoring different geohazards' spatial and temporal variations can be done reliably with InSAR. Moreover, some relations drawn between geohazards and their causing factors can be of value for future research.

\section{Materials and Methods}

Four application areas were addressed in this work; each focused on a type of geohazard, event or phenomenon. To improve both the document's readability and readers' experience, this section and the next-in which results are presented-will be divided in the same four application areas. Even so, data used in the research of each application area all came from thousands of satellite images acquired from ESA (Explorers and Sentinel), China and ESA third-party missions. Table 1 summarises the used EO data.

Table 1. Earth Observation (EO) data used in this work (Mission/Satellite I Number of images).

\begin{tabular}{cccccc}
\hline \multicolumn{2}{c}{ ESA Third-Party Missions } & \multicolumn{2}{c}{ ESA } & \multicolumn{2}{c}{ China } \\
\hline COSMO-SkyMed & 745 & Sentinel 1-A/B & 1740 & GF-3 & 12 \\
TerraSAR-X & 68 & Sentinel 2-A/B & 1657 & ZY-3 & 12 \\
ALOS & 48 & MSI & 255 & & \\
PlanetScope & 2 & ERS & 510 & & \\
\hline
\end{tabular}

Sentinel-1 (SAR C-band, $\sim 6 \mathrm{~cm}$ wavelength) and COSMO-SkyMed (SAR X-band, $\sim 3 \mathrm{~cm}$ wavelength) data were used to estimate glacial movements. Sentinel-1, ALOS-2 (Advanced Land Observing Satellite 2, SAR L-band, $23 \mathrm{~cm}$ wavelength), GF-3 (GaoFen Satellite 3; C-band, $\sim 6 \mathrm{~cm}$ wavelength) and ZY-3 imagery (optical sensor, $3 \mathrm{~m}$ resolution) were used to study land surface displacements within the Beijing area, namely to explore the benefits of recent remote sensing data for a detailed reconstruction of past displacement events and to monitor currently occurring phenomena. Optical data acquired by Sentinel-2 images - with spatial resolutions of $10 \mathrm{~m}$ - and PlanetScope data [56] — with a pixel size of $3 \mathrm{~m}$ (PlanetScope ortho scene product) - were used to reliably identify spatio-temporal landslides patterns. Finally, Sentinel-1, COSMO-SkyMed and TerraSAR-x (X-band, $\sim 3 \mathrm{~cm}$ wavelength) SAR images were used to identify landslides, buildings' inclination, land 
subsidence and fissures caused by overexploitation of traditional heavy industry based on the Benxi-Anshan-Shenyang-Fushun (BASF) region.

\subsection{Landslide and Ice Movement Identification and Monitoring near Typical Glacier Lakes}

Mountain glacier movement is directly related to the safety of both production and life in downstream villages and towns. Moreover, it is a sensitive witness and one important indicator reflecting global climate change. However, it is very complex to carry out field work for landslide, ice slide and glacial lake outburst flood risk management in the Tibetan plateau. Indeed, the very special geographic position and formidable natural conditions, make conventional methods-based on field work observations-not suitable to meet the requirements of the rapid monitoring and quantitative evaluation for the relevant geohazards.

Considering that surface deformation is the common characteristic for landslides, ice slides and glacier movements, advanced EO techniques may play a key role in risk management, mostly due to new generation high-resolution images, acquired by multi-satellites and multi-sensors. Therefore, the aim of doing research in this particular application area was to evaluate the suitability of EO-based systems for geohazards management, focusing on landslide, ice slide, and glacial lakes outburst floods (GLOF) in the Tibetan plateau (Figure 2). In the selected study area, there were glacier collapses and induced glacial lake outburst floods. Monitoring the surface movement of these glaciers is of great significance for the study of glacier collapse process and disaster prevention. Multi-temporal interferometry, pixel tracking and stereo measurement were all very relevant to perform this evaluation. These methods were applied for glacier movement, ice slide and landslide monitoring in different types of glacier areas, such as oceanic, sub-continental and continental glacier areas.

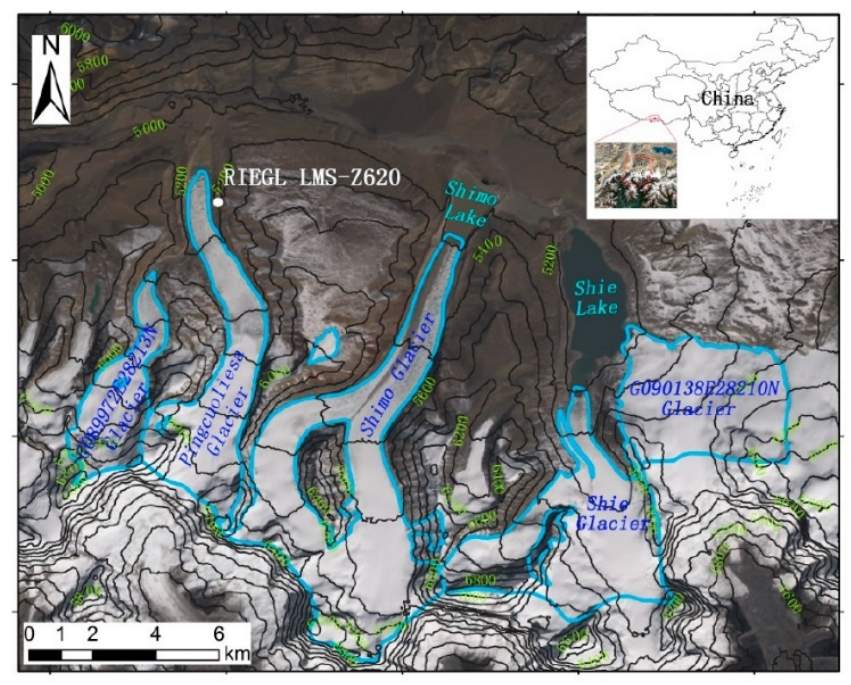

(a)

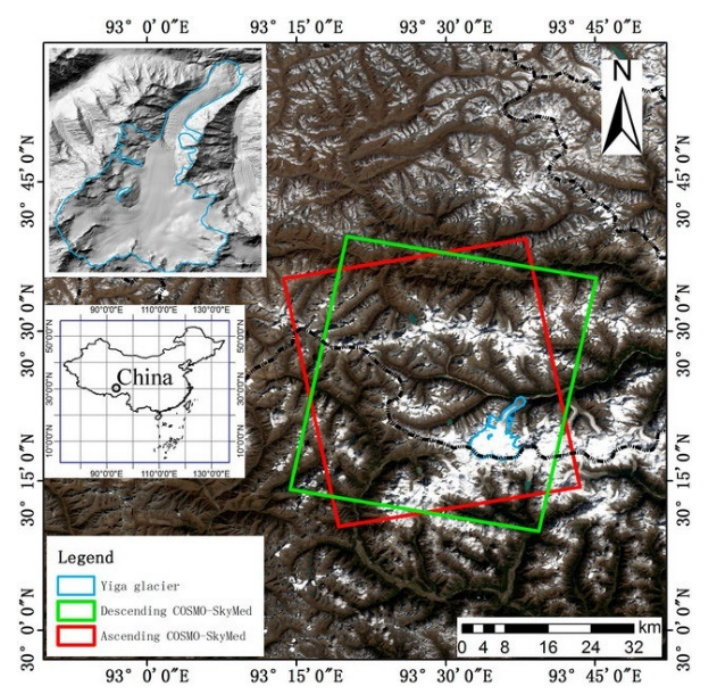

(b)

Figure 2. Glaciers studied in the scope of the Dragon 4 project. (a) The main results regarding these five glaciers were published in Fan et al. [57]. The solid blue line is the glacial range of The Second Glacier Inventory Dataset of China. (b) The location of Yiga Glacier and the coverage of Cosmo-SkyMed data.

The offset tracking technique-based on SAR image intensity information-was used to estimate glacier's displacement. It is effective even when velocities are high and the time interval between images is long, which allowed for its broad use in glacier velocity monitoring. Supported on Sentinel-1 data, velocity variation of Yiga Glacier from October 2014 to December 2017 was estimated by using the offset tracking technique, which has good resistance to the incoherent situation. Both the characteristics and possible causes of Yiga Glacier's velocity variation over time are analysed. This technique allows for the 
calculation of the range and azimuth offsets of SAR images by applying the normalized cross-correlation algorithm to the intensity information of SAR images. Furthermore, it has no requirements on the coherence of SAR images and can better resist the influence of image incoherence. Offset tracking is usually more suitable for areas that display obvious ground features [58].

Normalized cross-correlation (NCC) is the core of offset tracking technique. It mainly determines the matching degree of the template window in the reference image and the search window in the image to be registered by calculating the correlation coefficient. The size of the cross-relationship coefficient reflects the similarity between the template window and the search window. The principle is to select a specific template window in the main image, match it with the search window from the image and calculate the number of cross-relations for each position. When the value of the correlation coefficient is maximum, matching is completed, so as to obtain the total offset of the matched position [59-61]. Equation (1) allows the calculation of the correlation value coefficient in the normalized cross-correlation algorithm:

$$
\operatorname{NCC}(u, v)=\frac{\sum_{x, y}\left(f(x, y)-f_{r}\right)\left(g(x+u, y+v)-g_{s}\right)}{\sqrt{\sum_{x, y}\left(f(x, y)-f_{r}\right)^{2}} \sqrt{\sum_{x, y}\left((x+u, y+v)-g_{s}\right)^{2}}}
$$

where $(x, y)$ is the central coordinate of the template window, $(u, v)$ is the central coordinate of the search window, $f_{r}$ the average pixel value of the template window and $g_{s}$ is the average pixel value of the search window. When the value of $\operatorname{NCC}(u, v)$ is closer to 1 , the similarity between the two is greater. When the value of correlation coefficient is the maximum, it indicates that the registration of the two images is completed. The offset between the template window and the search window can then be calculated.

\subsection{Monitoring Land Surface Displacement Geohazards Using Multi-Temporal SAR Techniques}

Landslides may have catastrophic consequences for those living in landslide-prone areas. In general, landslides occur on steep, unstable slopes. The triggering of a catastrophic landslide movement is usually associated with intense and extreme rainfalls. However, before these occurrences there is always evidence that a particular landslide remains or became active. This may be of help to local authorities so that they can made supported decisions based on a given area's hazard level. Research done in this application area aimed at assessing multi-band SAR interferometry techniques suitability to detect landslide movement evidence.

To obtain the overall deformation distribution over extensive areas, a remote sensingbased approach is necessary. The combination of ground displacement (or velocity) estimates from ascending and descending satellite passes, imaging the same ground element from two widely different angles allows us to derive also the Up and East components of the deformation and can help to fill gaps in the occlusion and layover areas caused by the side-looking geometry of SAR sensors. Besides, the availability of a multi-sensor and multi-angle coverage can provide additional constraints for an optimal numerical modelling of the ground motions.

MT-InSAR techniques can be seen as an extension of the conventional InSAR techniques. Therefore, to overcome the limitations of traditional Multi-temporal interferometry techniques, Distributed Scatterers (DS)-InSAR along with Permanent Scatterers (PS)-InSAR [62] have to be extracted and used. Its similar statistical characteristic could be potentially employed in maximizing the spatial sampling of deformation signal over rural regions. Therefore, both PS and DS targets can be combined and be useful in the comprehensive investigation of the deformation. The selection of both DS targets and PS points are jointly processed without the need for significant changes in traditional Multi-temporal interferometry processing chain.

The Beijing area was selected to study landslide hazard and land subsidence by employing the described DS-InSAR and PS-InSAR combination method and the traditional 
Multi-temporal interferometry (SBAS-InSAR) to ALOS-2 (from February 2007 and January 2011) and Envisat (between August 2007 and June 2008) imagery, to increase the number of measurements (DS + PS points). The topographic phase was simulated and removed from the interferograms using the SRTM (Shuttle Radar Topography Mission) digital elevation map (DEM) [63] of 1-arc-second resolution. Sentinel-1 full swath IW mode SAR time series processing presents a huge challenge, due to its much larger coverage when compared with ENVISAT and ERS SAR data. For that reason and to ensure the temporal continuity in the processing, the SBAS approach implemented in StaMPS [64,65] was modified and used SSDS (SAR Subsidence Demonstration System) [66]. In the specific case of land subsidence, the displacements obtained in the line-of-sight (LOS) direction are translated to vertical direction based on a simple assumption that no horizontal ground motion occurred for subsidence monitoring applications $[67,68]$.

\subsection{Spatio-Temporal Landslide Identification and Activity Assessment for Hazard and Risk Investigations}

Spatial scale has been recognized as a key topic in the field of landslide identification, which considers the sensor's spatial resolution as well as the size of the features to be detected (i.e., landslides). Very high resolution imagery from commercial satellites-such as Geoeye or DigitalGlobe- - have shown a high potential in mapping smaller landslide features $[54,69]$. In contrast, medium resolution images—such as Landsat and Aster (30 m) are more adequate for rapid mappings and applications for large areas [70]. Sensors with a resolution in-between — such as Spot and RapidEye-have been used to establish a retrospective long-term multi-temporal landslide mapping based on a multi-sensor remote sensing time series [71]. ESA's Copernicus programme provides a unified system through which vast amounts of data are fed into a range of thematic information services, designed to benefit the environment, the way of live, humanitarian needs and support effective policymaking for a more sustainable future. Copernicus provides free optical high-resolution imagery from Sentinel-2. However, it remains unclear if the resolution remains too coarse to resolve smaller landslide features. To understand the impact of spatial scale, the Nyquist-Shannon sampling theorem offers useful rules of thumb for the pixel-based landslide recognition. It states that the dimension of the smallest detectable feature in a raster image is at least twice the size of the sensor resolution that was used to identify the feature (e.g., $50 \mathrm{~m} \times 50 \mathrm{~m}$ landslide should be detectable within $<=25 \mathrm{~m}$ raster imagery). Narrow landslide features should be registered by at least two cells in width direction, while also the local contrast plays a role in the detectability of spatial features. In case an object exhibits high local contrasts with its neighbourhood, such as substantial dissimilarities in luminance, even smaller features are detectable $[72,73]$.

Research developed in this particular application area draws on aspects of the NyquistShannon sampling theorem by investigating the efficiency of supervised and unsupervised landslide mappings based on change detection by comparing two different sensors. To this end, results based on freely available Sentinel-2 data-coarser resolution-were confronted with results based on high-resolution optical data from the Planet mission. Since a classical landslide map depicts binary information (i.e., presence and absence of landslides) and change detection approaches usually produce continuously scaled raw outcomes (e.g., likelihood of one class), two conceptually different approaches for defining the binary threshold were further tested. Results of an unsupervised method (the conventional procedure) were compared with the results of a supervised approach (based on mapped ground-truth information) to gain further insights into potential advantages and pitfalls of increasingly popular fully automated procedures that are supposed to work without the existence of ground truth information.

The conducted supervised classification was based on a Generalized Additive Model (GAM) that represents an extension of a Generalized Linear Model (GLM). A binomial GAM was used to model non-linear relationships between the binary response (landslide presence vs. absence observations) and the four change variables representing the spectral band differences (pre- vs. post-event). The resulting GAM-based probability maps for 
both, Sentinel-2 and PlanetScope data, were validated using the independent validation data and the Area Under the Receiver Operating Characteristic (AUROC) curve [74]. The AUROC represents a global measure that depicts how well a continuously scaled outcome (e.g., landslide probability between 0 and 1 ) discriminates a binary response (e.g., landslide presence and absence) from all possible threshold values. Furthermore, the ROC curve was also used to classify the continuously scaled maps into two classes: landslide areas and non-landslide areas. The optimized trade-off between correctly classified landslide presence observations and correctly classified landslide absence observations (i.e., the threshold maximizes the sum of sensitivity and specificity) was derived on the basis of the training observations. The validation samples to quantify the accuracy of the change maps and obtained sensitivity, specificity and overall accuracy was used [74,75].

The unsupervised approach was based on the Change Vector Analysis (CVA) and the Expectation-Maximization (EM) algorithm. CVA is a widely applied bi-temporal change detection approach that transforms spectral differences between images into two layers of intensity and direction of change. The method can be applied to any number and combination of spectral bands, ranging from two to $\mathrm{n}$ bands [76]. For this study, $\mathrm{CV}$-intensity for the spectral bands common to both sensors was calculated and the values were normalized between 0 and 1 to allow a comparison with the supervised approach on the basis of the AUROC. This map was then classified into landslide presence and absence pixels by applying the EM algorithm that is frequently used for unsupervised global image histogram thresholding and for change detection in remote sensing [77-79]. In analogy to the supervised approach, we used the test data set to assess the accuracy and derive the same validation measures as for the GAM [74,75].

The Longnan region is at risk for damage-causing slope instabilities and among the most landslide-prone regions in China. More than 500 landslide fatalities were registered within the last decades in the area (China Geological Survey Bureau of Statistics, 2008).

Reliable and multi-temporal landslide inventory maps allow further investigations, such as landslide hazard or risk assessments, and directly support local authorities. The start of the Copernicus Sentinel-2 mission in 2015 opened up new possibilities for developing and testing change detection approaches to map landslides using freely available high-resolution optical data. Compared to previous attempts based on freely available data from ASTER or Landsat, landslide recognition approaches based on Sentinel-2 data can provide results at a higher spatial detail. A systematic comparison between (un)supervised classification approaches based on high-resolution and freely available Sentinel-2 data and very high-resolution commercial satellite imagery is expected to provide deeper insights into potential advances and pitfalls of using Sentinel-2 data for the purpose of landslide recognition and addressing magnitudes of trade-offs in landslide mapping accuracies compared to higher resolution commercial data.

Copernicus provides freely available optical high-resolution imagery from Sentinel-2. However, so far it remains unclear how well different approaches (i.e., supervised and unsupervised classification) perform to map landslide features of different dimensions using both Sentinel-2 data and very high-resolution commercial satellite imagery.

\subsection{Collaborative Monitoring of Multiple Geohazards with Multi-Source Remote Sensing Data}

MT-InSAR is able to overcome the spatio-temporal decorrelation and atmospheric phase artefact problems that prevent traditional differential InSAR technique from being a useful tool in deformation monitoring. With the rapid development of SAR instruments and availability of SAR images, MT-InSAR has been widely applied in large scale monitoring of precise deformation caused by subsidence, landslides, earthquakes and volcanic activities, etc.

Research in this application area is aimed at understanding associations between multiple geohazards and their causing factors, by means of MT-InSAR, e.g., [16,62], particularly by exploiting both the Permanent Scatterers and the Small BAseline Sub-set approaches. On the one hand, the two methods cross validate their own outputs. On the other hand, 
we can exploit their complementarity, allowing to measure different spatial and temporal scales of the deformation processes with the analysed areas. Moreover, in this way, it will be possible to extend the analysis of a single disaster to modelling the complicated associations amongst multiple disasters and their causing factors. To this end and taking advantage of the huge availability of remote sensing data sets to analyse the various geohazards and environmental problems in traditional heavy industrial regions, the BenxiAnshan-Shenyang-Fushun (BASF) region, located in Liaoning Province, northeast China, was chosen as a study area (Figure 3). As already presented, the main threats in this area are landslides of mining pits and dump sites, subsidence, ground fissures that often reflect in structural degradation of buildings, possible dam break of tailings ponds, etc. Therefore, continuous and precise monitoring of the spatial and temporal variations of multiple geohazards in this BASF area is important for early warning and risk assessment.

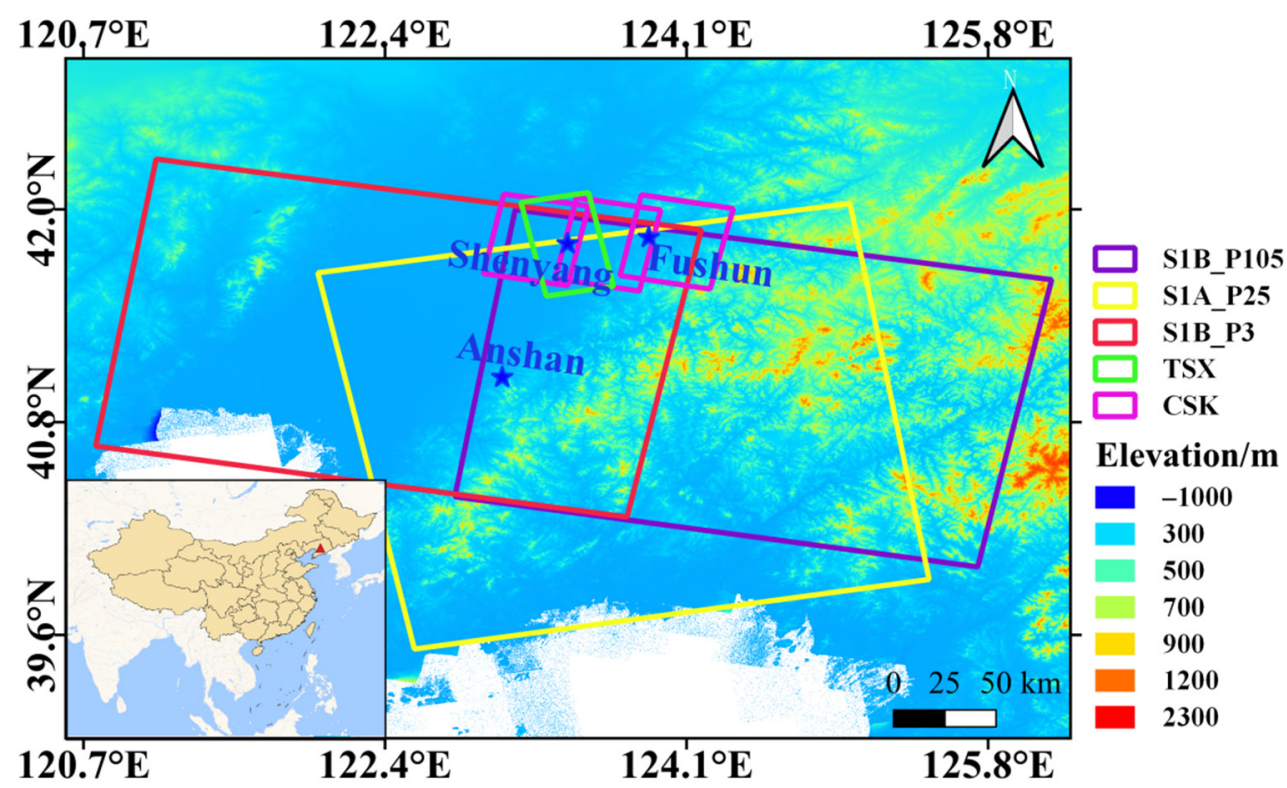

Figure 3. Study area and coverage of Synthetic Aperture Radar (SAR) datasets.

Indeed, instead of only monitoring a single geohazard, this research reveals the spatiotemporal process and complicated associations of multiple geohazards and analyses their main causing factors (e.g., mining excavation, mining bursting, underground construction, ground water extraction and earthquake) via data modelling and assimilation technique. It is worth to note that to detect and to measure the deformation processes that have different spatial gradients and different temporal trends, we take the advantage of both C-band medium-resolution (Senitnel-1) and high-resolution X-band (COSMO-SkyMed and TerraSAR-X) SAR images.

\section{The Project's Outputs}

This section presents the results obtained for each of the four application areas addressed in this work.

\subsection{Landslide and Ice Movement Identification and Monitoring near Typical Glacier Lake}

The Yiga Glacier (Figure 2b), located in the western section of Nyainqing Tanggula Mountains, Jiali County, Tibet, China, was chosen to be studied for this application area. According to the Second Glacier Catalogue of China released by Cold and Arid Regions Environmental and Engineering Research Institute of the Chinese Academy of Sciences in 2014, the area of Yiga Glacier is about $46.3 \mathrm{~km}^{2}$, and the height difference is close to $3000 \mathrm{~m}$ [80]. The movement of the Yiga Glacier, which is connected with Niduzangbu, is likely to block the river channel and form barrier lakes, threatening the safety of many 
downstream villages. Therefore, it is very important to monitor the glacier's movement. A total of 25 Sentinel-1 images, acquired with 48 days' interval, are time sequenced. Then, 24 time-series offset tracking results are generated, and the results are converted from the SAR coordinate system to the geographic coordinate system. Results are shown in Figure 4. The quantitative results are presented in Table 2.

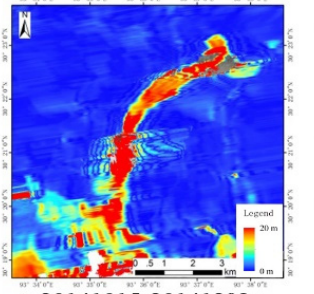

20141015-20141202

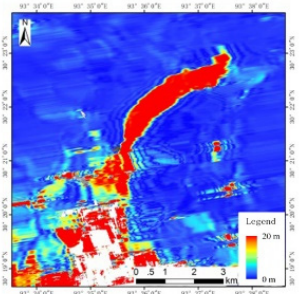

20150425-20150612

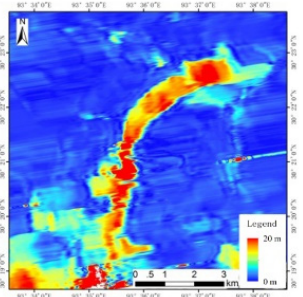

20151103-20151221

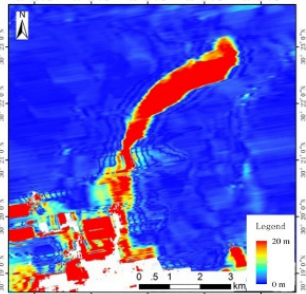

20160513-20160630

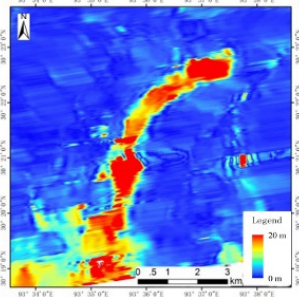

20161121-20170108

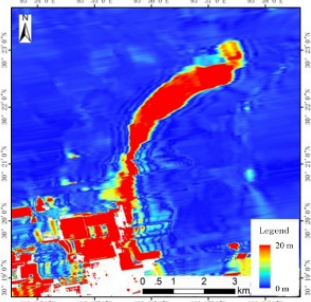

20170601-20170719

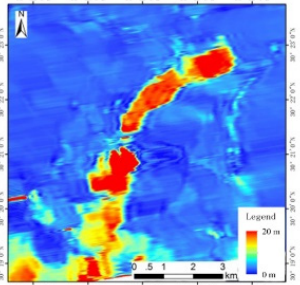

20141202-20150119

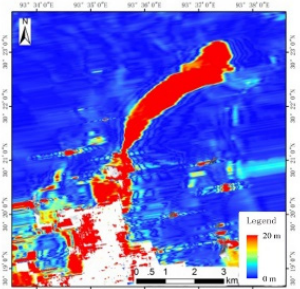

20150612-20150730

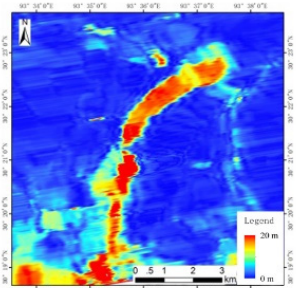

20151221-20160207

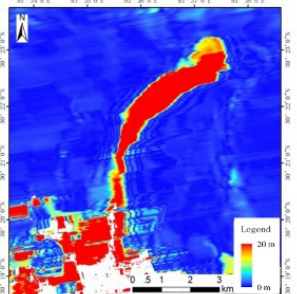

20160630-20160817

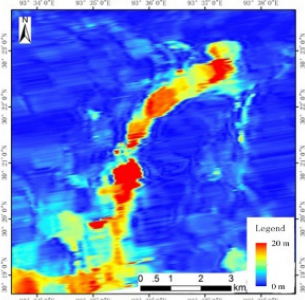

20170108-20170225

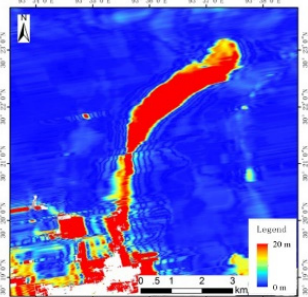

20170719-20170905

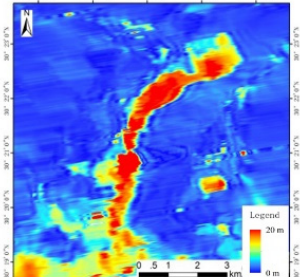

20150119-20150308

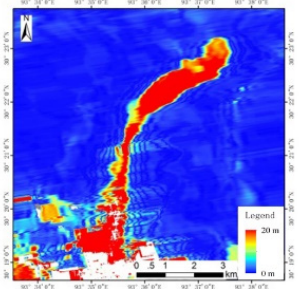

20150730-20150916

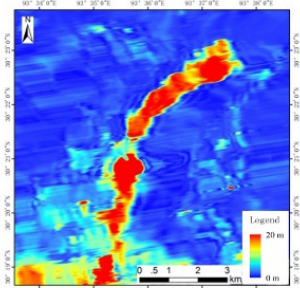

20160207-20160326

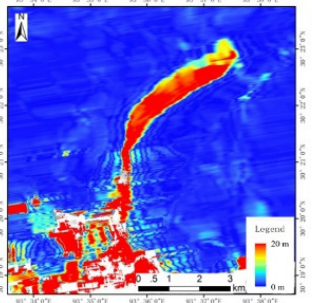

20160817-20161004

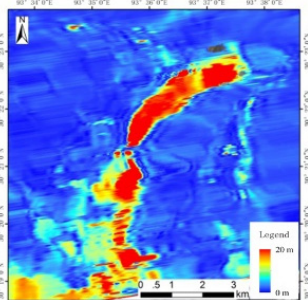

$20170225-20170414$

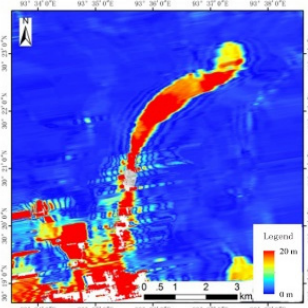

20170905-20171023

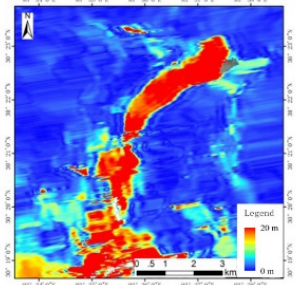

20150308-20150425
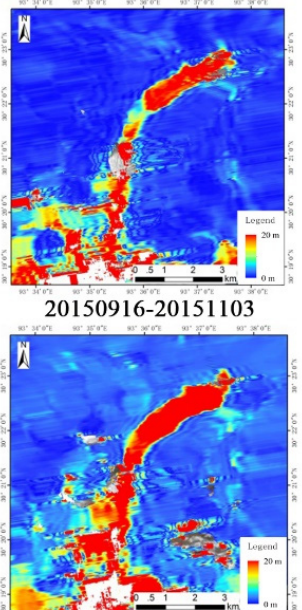

20160326-20160513

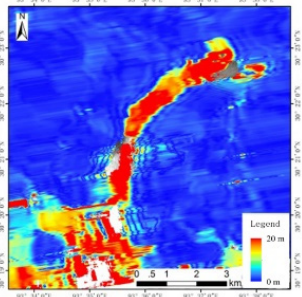

20161004-20161121

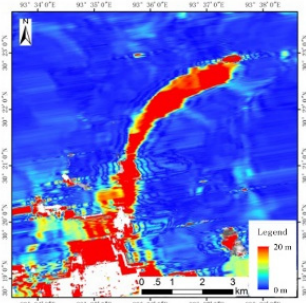

20170414-20170601

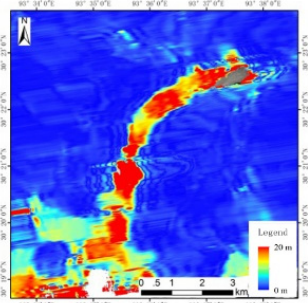

20171023-20171210

Figure 4. Movement distribution of the Yiga Glacier between 15 October 2014 and 10 December 2017. 
Table 2. Surface displacement and mean velocity of the Yiga Glacier.

\begin{tabular}{ccc}
\hline Image Pairs & Displacement $(\mathbf{m})$ & Velocity $(\mathbf{c m} /$ Day) \\
\hline $20141015-20141202$ & 18.15 & 37.80 \\
$20141202-20150119$ & 18.22 & 37.95 \\
$20150119-20150308$ & 19.57 & 40.77 \\
$20150308-20150425$ & 20.30 & 42.30 \\
$20150425-20150612$ & 22.04 & 45.92 \\
$20150612-20150730$ & 23.44 & 48.84 \\
$20150730-20150916$ & 21.51 & 44.81 \\
$20150916-20151103$ & 17.13 & 35.69 \\
$20151103-20151221$ & 16.39 & 34.15 \\
$20151221-20160207$ & 18.09 & 37.70 \\
$20160207-20160326$ & 19.13 & 39.86 \\
$20160326-20160513$ & 22.85 & 47.61 \\
$20160513-20160630$ & 21.97 & 45.77 \\
$20160630-20160817$ & 24.05 & 50.10 \\
$20160817-20161004$ & 19.89 & 41.44 \\
$20161004-20161121$ & 19.11 & 39.82 \\
$20161121-20170108$ & 16.89 & 35.20 \\
$20170108-20170225$ & 16.14 & 33.63 \\
$20170225-20170414$ & 20.17 & 42.03 \\
$20170414-20170601$ & 21.93 & 45.70 \\
$20170601-20170719$ & 21.58 & 44.96 \\
$20170719-20170905$ & 22.69 & 47.27 \\
$20170905-20171023$ & 20.37 & 42.43 \\
$20171023-20171210$ & 17.28 & 36.00 \\
\hline
\end{tabular}

Due to the difference in the acquisition time of SAR images and in the SAR satellite imaging angle, the velocity distribution range of the Yiga Glacier surface-obtained by using the offset tracking technique based on Sentinel-1 images-is different to some extent. To better analyse the relationship between the Yiga Glacier velocity over time and why it has changed in the past three years, the regions with stable measurement results in the 24 groups of results were selected. The variation of the average Yiga Glacier surface velocity in time is shown in Figure 5. The average value of the glacier's surface velocity in the region was calculated for time-series analysis. A detailed study about the monitoring and analysis of mountain glacier surface movement using SAR data and a terrestrial Laser Scanner in the Himalayas North Slope Glacier Area (relative to glaciers presented in Figure 2a) is presented in Fan, J. et al. [57]. It has the full results of Dragon 4 (ID 32365) project regarding this application area.

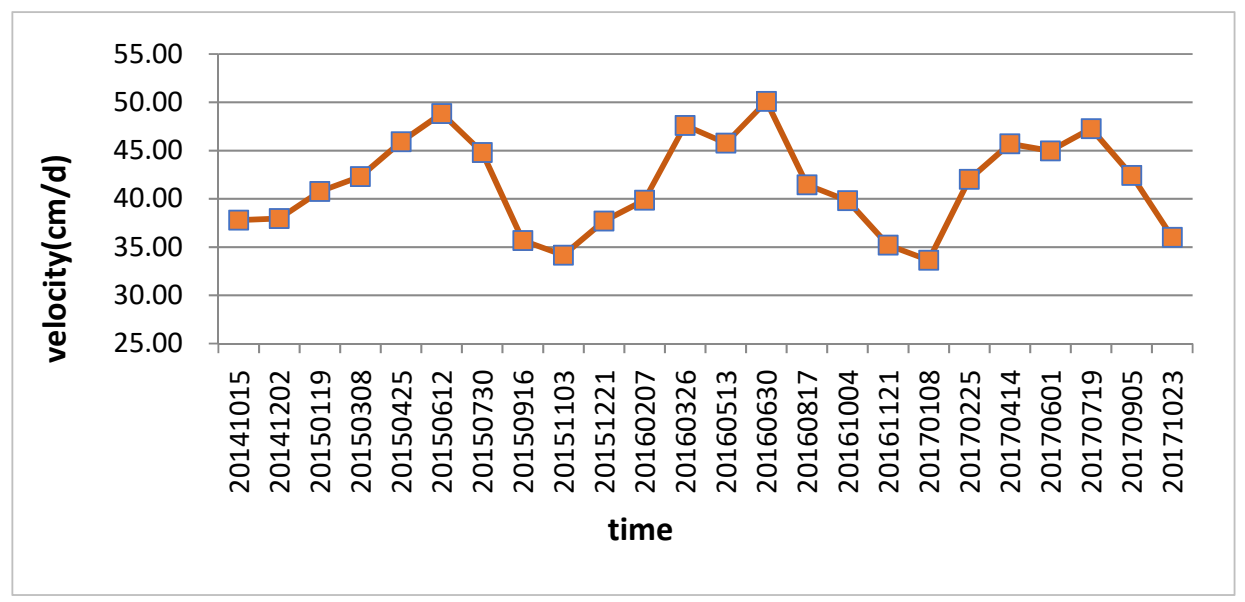

Figure 5. Variation, in time, of average surface velocity of Yiga Glacier. 
According to Figure 5, and Table 2, it can be seen that the average glacier's surface velocity of the Yiga Glacier has shown a stable trend with time over the past three years, essentially showing the characteristics of change from winter to summer, when the glacier's surface velocity rises, reaching its maximum in summer, and from summer to autumn and winter, when the glacier's surface velocity decreases. The maximum average glacier's surface velocity during the monitoring period was $50.1 \mathrm{~cm} / \mathrm{d}$ between 30 June 2016 and 17 August 2016, and the minimum average glacier's surface velocity was $33.63 \mathrm{~cm} / \mathrm{d}$ between 8 January 2017 and 25 February 2017.

\subsection{Monitoring Land Surface Displacement Geohazards Using Multi-Temporal SAR Techniques}

The Huabei Plain land subsidence area, affecting a mega-city group that includes the area around Beijing and Tianjin, was selected as the study area. Groundwater overexploitation for residential consumption has caused a series of land subsidence events [81]. Until now there have only been small crop areas monitored around Beijing with Sentinel-1 SAR data [82], covering about $5 \times 10 \mathrm{~km}^{2}$ (one-tenth of the full swath).

In general groundwater, overexploitation for residential consumption results in slow land subsidence. This kind of ground subsidence is always smaller compared with coseismic deformation, which needs to accumulate temporally to obtain obvious effect. The Sentinel-1 data in TOPS IW mode, acquired in 2017, was processed with the SBAS method. The linear subsidence velocity map is shown in Figure 6, in which more than $4 \times 10^{7}$ stable points were obtained within $8 \times 10^{7}$ initial selected points with the amplitude dispersion threshold method. These results show that the largest subsidence happened at the border between Hebei and Tianjin and at the central area in the Hebei province. Both are greater than $0.1 \mathrm{~m} /$ year. Some obvious subsidence evidence areas also presented in southeast of Beijing. Figure 6 also presents a zoom-in around Tianjin West, which depicts a clear subsidence centre. The Phase II of South-to-North Water Diversion Project in the future will slow these significant deformations.

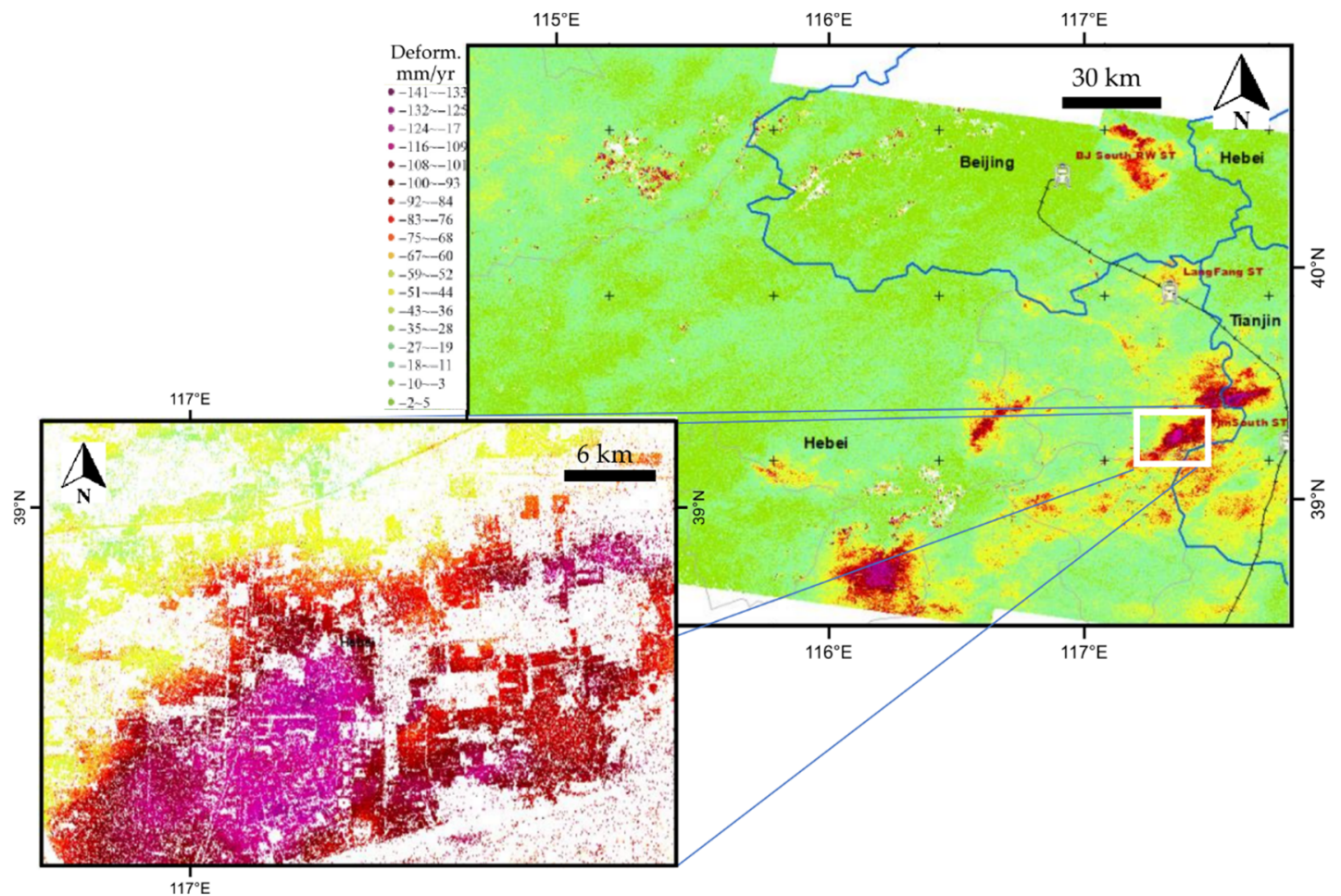

Figure 6. Sentinel 1 TOPS IW mod Small BAseline Sub-set (SBAS) subsidence map of Beijing South, with an enlarge subsidence map around Tianjin West. 
Figure 7 presents the subsidence map of Beijing as obtained from SBAS processing of C-band GF-3 data. The subsidence pattern and the magnitude match the Sentinel-1 results. In both cases, there is a clear subsidence in the southeast part of Beijing. These results allow us to conclude that the groundwater level, changing due to overexploitation, is highly correlated with the spatial and temporal distribution of land subsidence in the Huabei plain area. Full results and interpretation from Dragon 4 (ID 32365) project regarding landslides monitoring over rugged mountain areas can be found in [83].

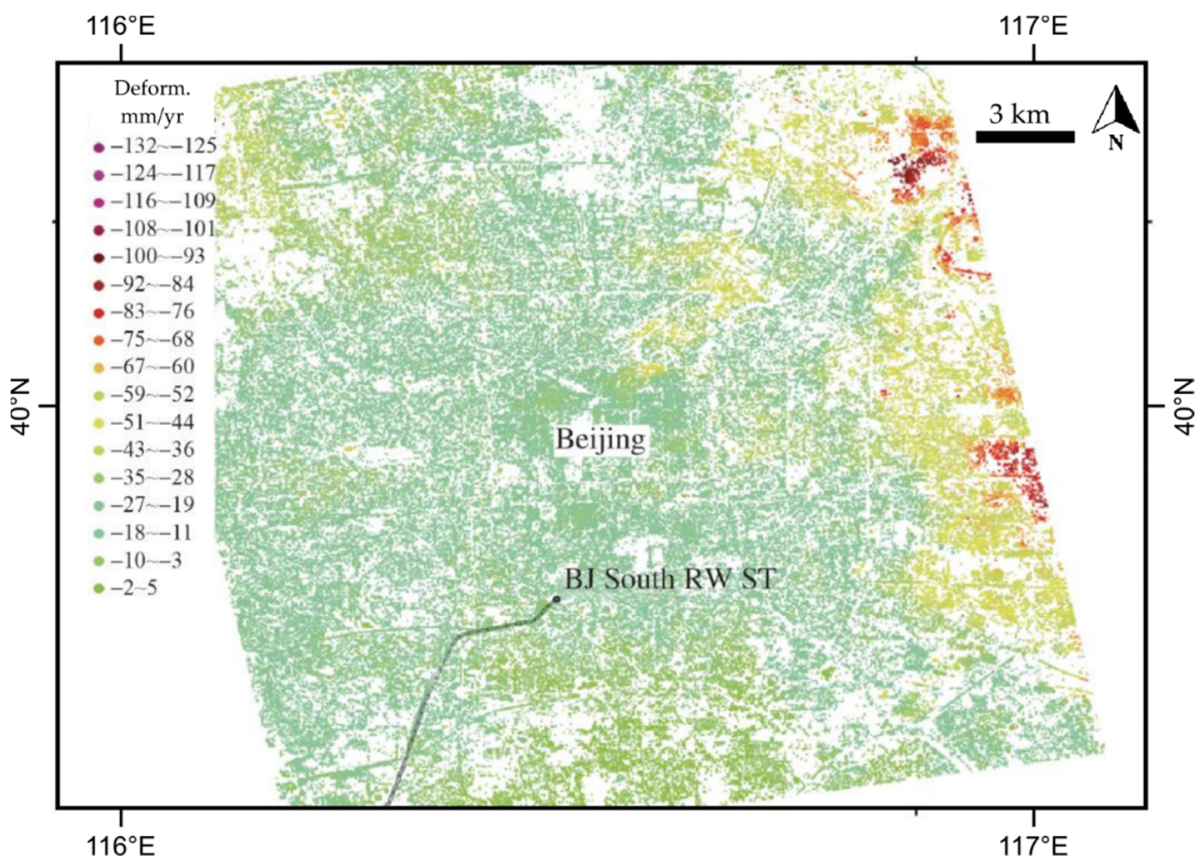

Figure 7. GF-3 SBAS subsidence map of Beijing.

\subsection{Spatio-Temporal Landslide Identification and Activity Assessment for Hazard and} Risk Investigations

Mapping accuracies varied between approaches and sensors (Table 3). GAM generally outperformed the automatic threshold of CVA intensity values, and slightly higher accuracies were obtained for PlanetScope data $(\mathrm{GAM}$, overall accuracy $=0.86)$ than for Sentinel-2 data (overall accuracy $=0.84$ ). Likewise, for the EM approach, higher accuracies were achieved by PlanetScope data compared to bi-temporal Sentinel- 2 images, although the difference between accuracies was more pronounced (overall accuracies: 0.77 and 0.70). Sensitivity values ranged between 0.73 to 0.92 for PlanetScope for both methods, while specificity values were the same. For Sentinel-2, sensitivities were similar- 0.81 and 0.84 , respectively. However, specificity values were low for the Expectation Maximization approach (0.58) but relatively high for the Generalized Additive Model (0.84). In general, the accuracy measures suggest a higher mapping performance based on PlanetScope data compared to Sentinel-2 data and a higher proportion of correctly mapped landslides and non-landslide areas when using the GAM instead of the unsupervised classification (EM).

Table 3. Mapping accuracies using Expectation-Maximization (EM) and Generalized Additive Model (GAM) for Sentinel-2 and PlanetScope imagery.

\begin{tabular}{cccccccccc}
\hline & \multicolumn{2}{c}{ Sensitivity } & \multicolumn{2}{c}{ Specificity } & \multicolumn{2}{c}{ OA } & \multicolumn{2}{c}{ AUROC } \\
\cline { 2 - 9 } Sensor & EM & GAM & EM & GAM & EM & GAM & EM & GAM \\
\hline Sentinel-2 & 0.81 & 0.84 & 0.58 & 0.85 & 0.85 & 0.84 & 0.73 & 0.9 \\
PlanetScope & 0.73 & 0.92 & 0.81 & 0.81 & 0.81 & 0.86 & 0.83 & 0.93 \\
\hline
\end{tabular}

OA-Overall accuracy; AUROC — Area Under the Receiver Operating Characteristic. 
ROC curves were calculated for the raw outcomes and provided insights into the quality of the results before thresholding. General interpretation guidelines for ROC statistics indicate that an AUROC of 0.5 relates to a random model, while a value of 1 depicts a perfect discrimination result. Values between 0.7 and 0.8 are considered acceptable, while AUROCs between 0.8 and 0.9 point to an excellent discrimination [75]. In this work, the EM approach was associated with AUROC values of 0.73 for Sentinel-2 and 0.83 for PlanetScope, indicating an acceptable separability of the landslide-affected areas from the not-affected areas within the context of the conducted unsupervised classification (Table 3). The considerably higher AUROC values for the GAM approach (0.90 to 0.93) suggest an excellent discrimination of landslide areas from areas unaffected by slope instabilities.

The resulting change maps confirmed the mapping performance of the two approaches to a large extent (Figure 8). Most landslides were generally well delineated with both sensors, and the GAM change maps showed a higher agreement with the digitized landslide polygons. Differences between the detected landslides for the two sensors were mostly present at the landslide boundaries where only parts of the pixels were affected by a decline in vegetation cover. The result of this mixed pixel effect was more apparent for overall small landslides and landslide polygons with an elongated shape. The landslide areas mapped by the PlanetScope data thus showed rather smooth boundaries and included also smaller areas that remained undetected by the Sentinel-2 images.

Change maps derived with the automatic threshold using the EM approach were less accurate in delineating the landslide polygons and showed a considerable higher rate of pseudo-change at the same time.

A number of wrongly mapped areas could be identified, which lowered the classification accuracy. These areas are mostly agricultural fields but also include unchanged forest areas to some extent. Detected changes in the agricultural fields can be explained by differences in vegetation cover at the times when the satellite images were acquired. As such, these areas represent vegetation changes per se but are not related to a landslide phenomenon. In contrary, some unchanged forest areas that were classified as landslides are actual false positives, which increases the commission error. Visual confrontations confirmed that such effects were considerably stronger for Sentinel-2 images than for the PlanetScope data and were more evident when using the EM approach than the GAM approach.

The reference database used was generated by a trained expert who manually digitized the individual landslide polygons based on the high resolution PlanetScope data. While this approach is standard in creating landslide inventory data for large areas, some areas close to landslide boundaries or smaller spatial features were still classified as landslide areas by the algorithms, leading to an increase in the commission error. It remains open how many of these areas are actual false positives or a result of wrong geomorphic interpretations. Likewise, some digitized landslide areas included vegetation not at all or only marginally disturbed that was unresolved in the polygons, which introduced an overestimation of the actual landslide area and resulted in underestimation of the satellite-derived landslide area (omission error).

\subsection{Collaborative Monitoring of Different Geohazards with Multi-Source Remote Sensing Data}

A traditionally heavy-industry region-BASF-was chosen as a study area to look for associations between multiple geohazards and their causing factors. Results of this application area are structured by city to provide some further social and economic context. 


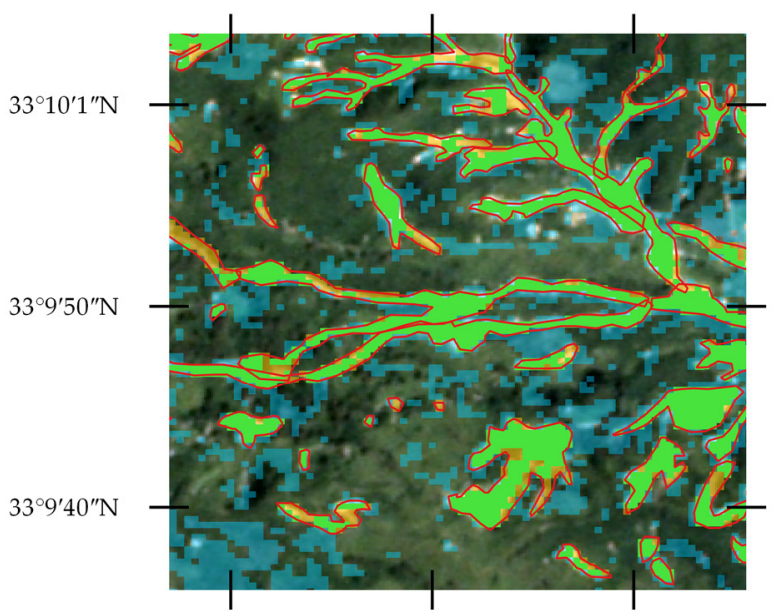

(a)

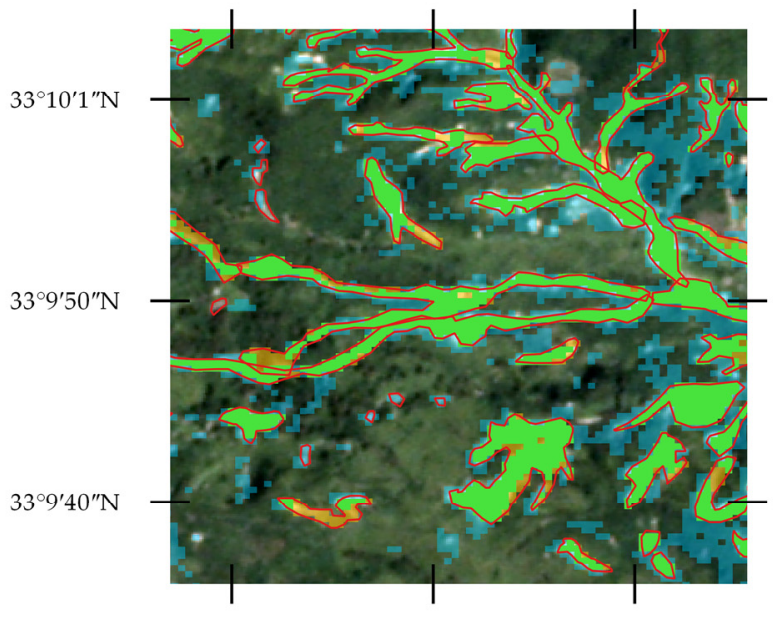

$104^{\circ} 38^{\prime} 17^{\prime \prime} \mathrm{E}$

$104^{\circ} 38^{\prime} 28^{\prime \prime} \mathrm{E}$

(c)

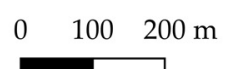

\section{Legend}

$\square \begin{aligned} & \text { Digitized reference landslides } \\ & \text { of type slide and debris flow }\end{aligned} \quad \begin{aligned} & \text { Detected landslide- } \\ & \text { affected areas }\end{aligned}$

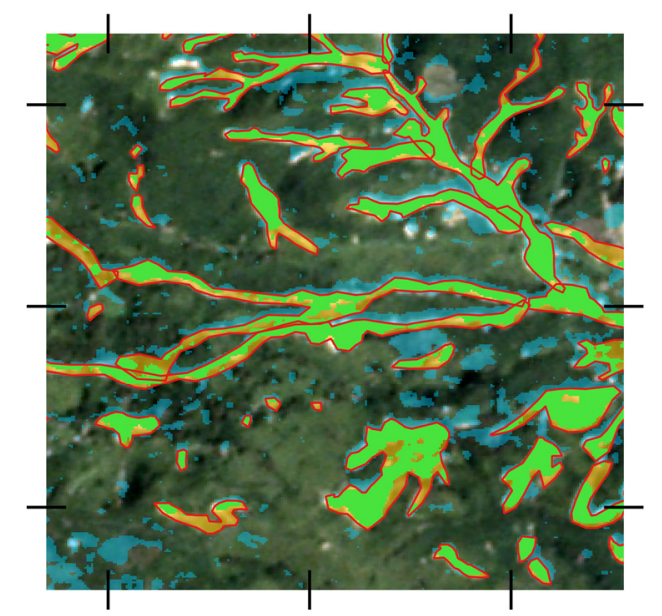

(b)

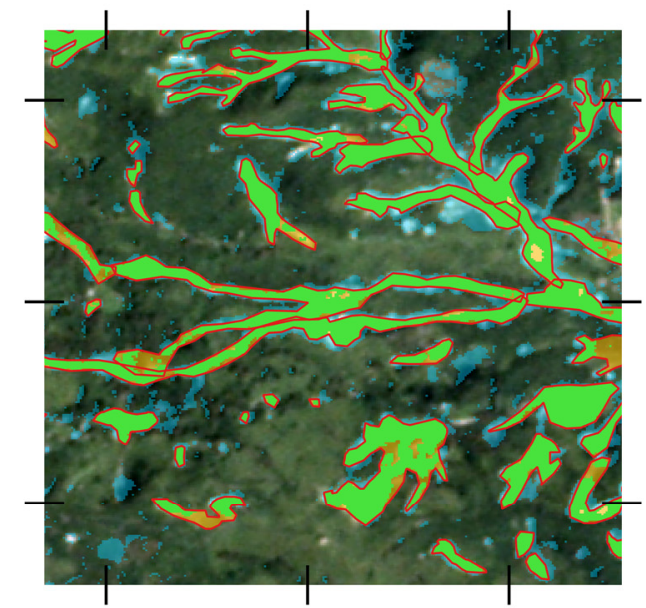

$104^{\circ} 38^{\prime} 17^{\prime \prime} \mathrm{E}$

$104^{\circ} 38^{\prime} 28^{\prime \prime} \mathrm{E}$

$104^{\circ} 38^{\prime} 38^{\prime \prime} \mathrm{E}$

(d)

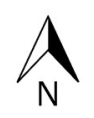

Figure 8. Results of the change detection: (a) Expectation-Maximization (EM) with Sentinel-2 imagery, (b) EM with PlanetScope imagery, (c) Generalized Additive Model (GAM) with Sentinel-2 imagery, and (d) GAM with PlanetScope imagery. The manually digitized landslide polygons are displayed in red by their outlines. The results of the change detection are colorized as indicated in the legend. The processing periods are 6 June 2018 and 1 July 2019 for Sentinel-2 and 6 June 2018 and 3 June 2019 for PlanetScope.

\subsubsection{Anshan}

Anshan is a heavy industrialized city located in northeast China, which is suffering from serious ground displacement caused by intensive mining activities, especially in areas close to the large open pit iron mines. Figure 9 presents displacement velocity maps in the satellites' LOS obtained by processing Sentinel-1 (Figure 9a-c) and CSK (Figure 9d), where the blue colour indicates targets moving towards the sensor and the red colour indicates targets moving away from the sensor, along LOS. All the maps are in very good agreement, providing the same deformation patterns and rates. The CSK dataset has a lower-point density because the X-band phase quickly de-correlates. Moreover, the shorter wavelength is not suitable to follow the fastest deforming areas, i.e., those closest to the pit mines. As shown in Figure 9, all the mining areas in Anshan are displacing rapidly. However, 
no pixels are detected at the bottom of the mining pits due to de-correlation caused by continuous mineral resource exploitation. Displacement velocities on some mining slopes present opposite signs in descending and ascending orbits. This is due to the different LOS and imaging geometry of descending and ascending data stacks.

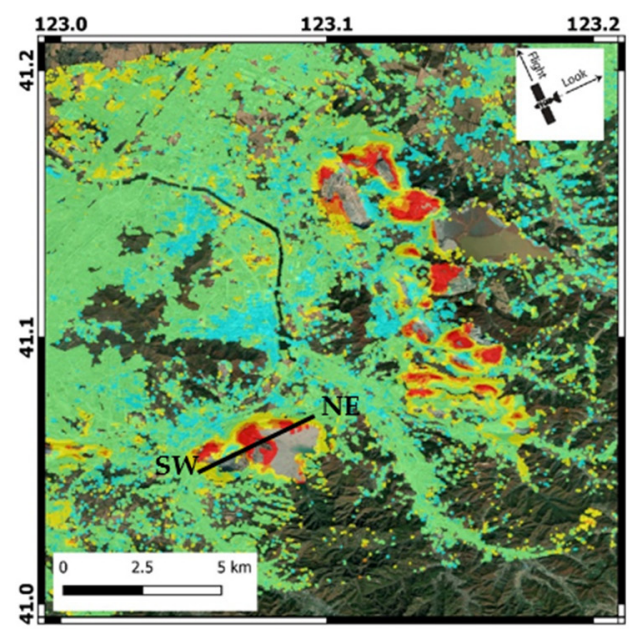

(a)

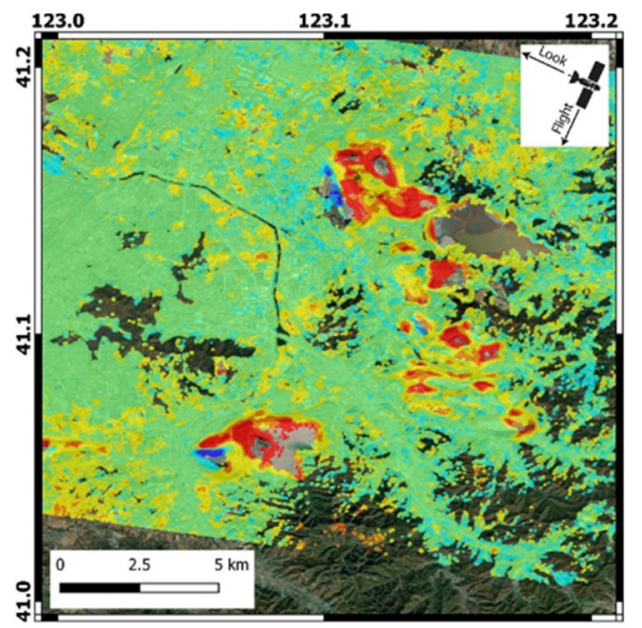

(c)

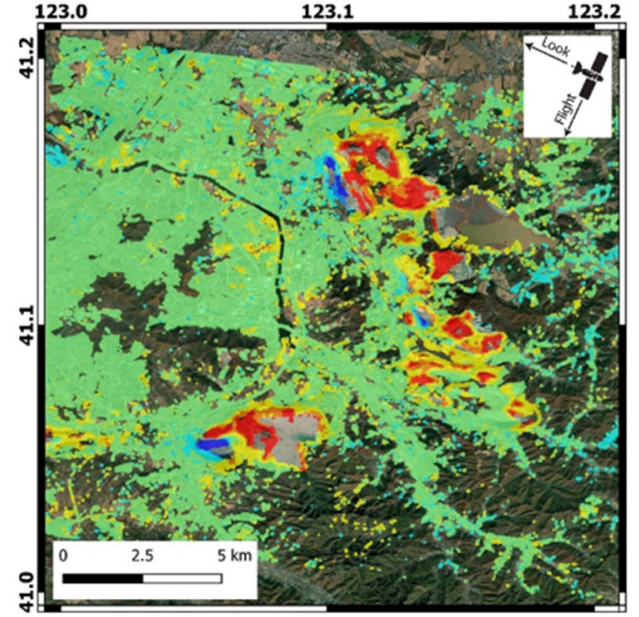

(b)

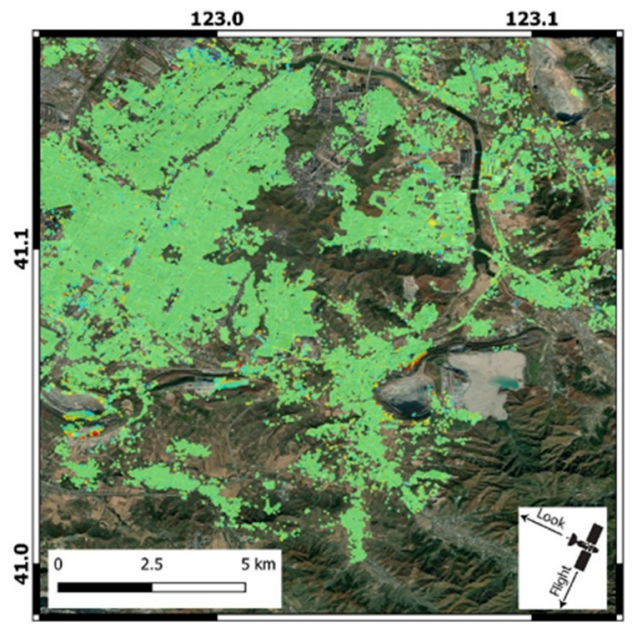

(d)

Figure 9. Ground velocity maps for the Anshan pit mine area: (a) S1 ascending on path 25; (b) S1 descending on path 105. Black line represents the profile plotted in Figure 3; (c) S1 descending on path 3; (d) COSMO-SkyMed (CSK) descending orbit. Note that CSK map has a different colour bar and different spatial scale and layer extent because of the CSK frame.

To further analyse this issue, Figure 10 presents the cumulated displacements along the SW-NE profile sketched in Figure 9a. The profile perfectly covers four different areas at this open pit mine, including the Dagushan open pit: the current waste dump, the old waste dump used before the year 2000, and the newly built tailing dam (constructed in 2016), as marked in Figure 10. Values for the three S1 measurements (Path 3, 25 and 105) are also shown in the same figure, as well as the corresponding altitude profile, respectively. The altitude profile was obtained using DEM data, freely available from the TanDEM-X mission, re-sampled at $50 \mathrm{~m}$ resolution. The descending measurements (related to the Path 3 and 105) are in very good agreement among them, even though some small differences are visible, likely due to the different LOS of the two adjacent tracks. 


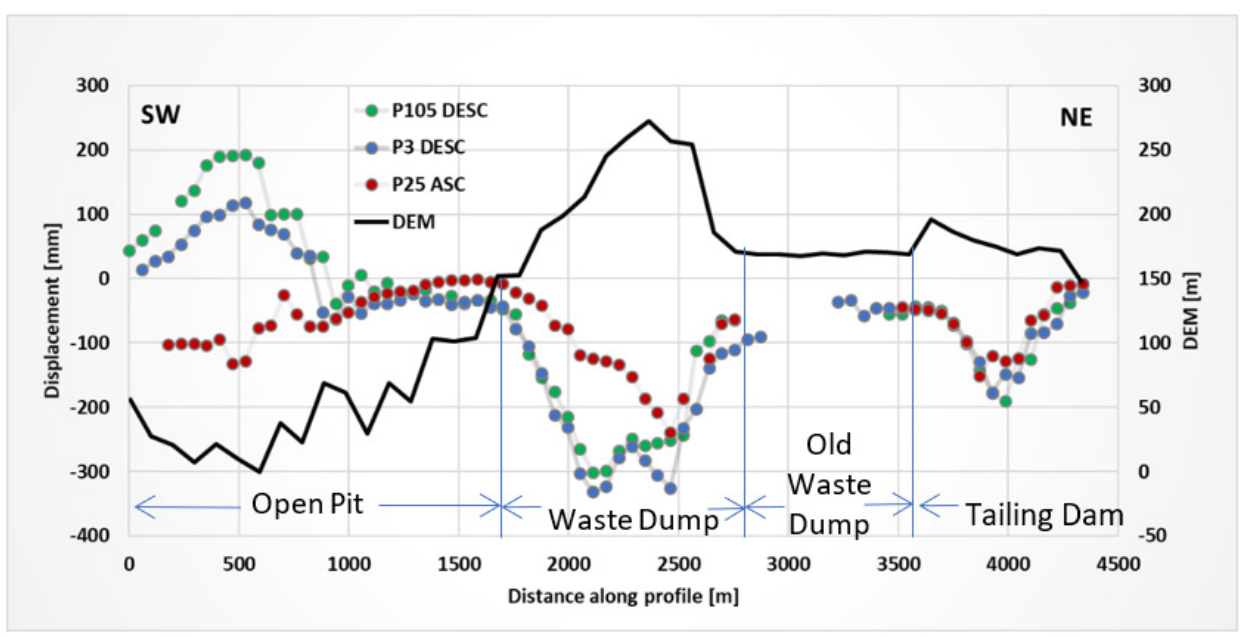

Figure 10. Cumulated displacement measured along the profile (SW-NE) depicted in Figure 9a. The plot reports the three S1 cumulated displacement (coloured dots) and the corresponding altitude profile (black continuous line) obtained by Global TanDEM-X-DEM.

Compared to the ascending data (Path 25), it can be noted on the left side of the profile, corresponding to the negative values of the elevation, where a positive convexity is present (between 0 and $1000 \mathrm{~m}$ ), opposite deformation with respect to the ascending data is presented. This area corresponds to a potential landslide area on the northwest slope, and the opposite values are caused by variation of LOS between ascending and descending orbits. The remainder of the open pit (between $1000 \mathrm{~m}$ and $1700 \mathrm{~m}$ ) is generally stable. This has been confirmed by engineering geologists. In the current waste dump area (between $1700 \mathrm{~m}$ and $2800 \mathrm{~m}$ ), severe displacement has been detected by all three stacks. This is due to consolidation of the loose pile structure of fragmented rocks in the waste dump, resulting in both vertical and horizontal movements of the SAR targets. The old waste dump (between $2800 \mathrm{~m}$ and $3600 \mathrm{~m}$, and positive convexity of the DEM), which was used 20 years ago, is generally stable now, with maximum displacements smaller than $50 \mathrm{~mm}$. This points out that the old waste dump area has completed consolidation. The tailing dam (starting from $3600 \mathrm{~m}$ ) is reported to share identical cumulated displacement in all three stacks, which indicates a pure vertical and downward motion. This part of the tailing dam was built in 2015 by rolling the mining wastes. Compared with the open pit area, the tailing dam can be approximated as a relatively flat area. Therefore, the deformation is generally in the vertical direction.

\subsubsection{Fushun}

Fushun is a city that has been built on the coal mining industry for approximately 120 years, with many underground and open-pit coal mines. Fushun West Open Pit (FOP), located in the southwest of Fushun city, is the largest open pit mine in Asia. After continuous mining since 1901, a large open pit with $6.6 \mathrm{~km}$ from east to west and $2.2 \mathrm{~km}$ from north to south has formed, with a depth of approximately $418 \mathrm{~m}$ and spatial coverage of $10.86 \mathrm{~km}^{2}$. Since the 1920s, more than 90 landslides have happened in FOP, especially due to the intensive mining activities in 1986, threatening the safety of neighbouring residential buildings, plants and equipment around the mine. The displacement velocity maps and plots of time series by S1 and CSK are reported in Figure 11. Displacement maps both show that the central part close to the north slope (where the former powerplant was located) was deforming at a fast pace during 2015 and 2017. Indeed, landslides have happened three times on the central part of the north slope, in the summers of 2014, 2015 and 2016, respectively, after heavy rainfalls. After the 2016 landslide, the north slope was reinforced. Therefore, it is worth to note that, until July/August 2017, S1 and CSK time series highlight a very similar linear trend, whilst after, S1 shows a decrease in the deformation velocity. 


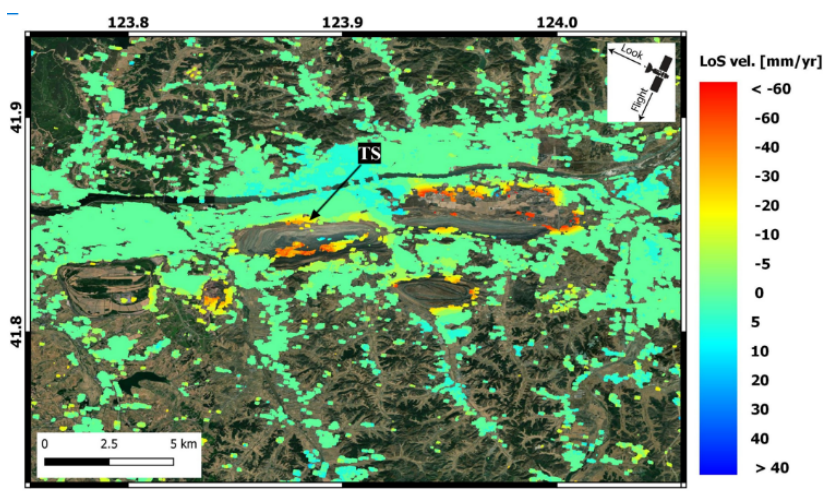

(a)

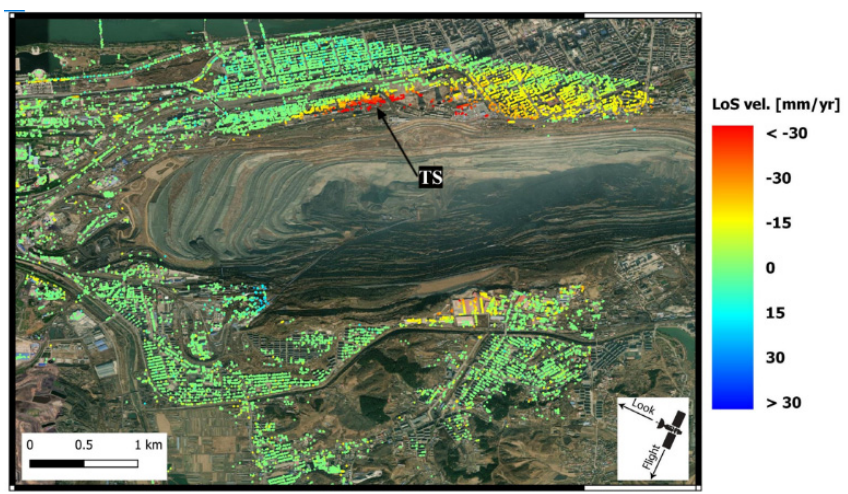

(b)

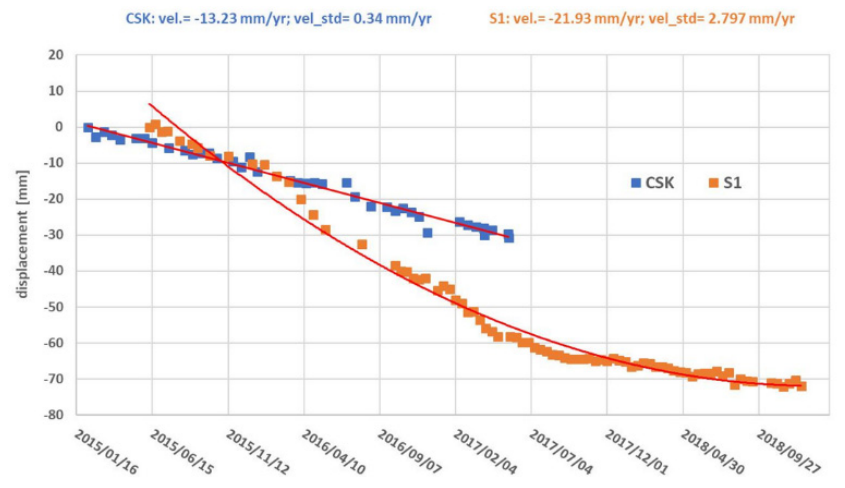

(c)

Figure 11. Ground velocity maps for the Fushun pit mine area. (a) S1 ground descending velocity map; (b) CSK ground descending velocity map; (c) displacement time series for the Persistent Scaterrer (PS), marked as TS in (a) and (b), measured by COSMO-SkyMed data (blue symbols), and S1 (orange symbols).

It is worth to also note that S1 shows a higher deformation rate with respect CSK for the overlapping period. This is likely due to the short wavelength of CSK $(3 \mathrm{~cm})$ that does not allow for accurately following the fast movements in this part of the mine. S1, with its $5.6 \mathrm{~cm}$ wavelength, is (as expected) more suitable for monitoring faster deformation trend. However, other factors that could explain the difference measurement along the LOS are: (i) the different incidence angles of the two sensors with respect to the buildings orientation and (ii) a different position of the Ground Control Points adopted to estimate and remove possible orbital ramps resulting in a residual small offset between the two final products.

Unfortunately, we do not know the actual movements direction; therefore, it is not very easy to fully justify the different velocities.

\subsubsection{Shenyang}

Shenyang is the capital city of Liaoning province in northeast China. Underground construction of subway lines has been continuously done in recent decades, resulting in continuous subsidence around the city, especially along subway lines. Displacement velocity maps derived from CSK and TSX images are shown in Figure 12. They have shown very good agreement with each other, even though it is a qualitative analysis due to the limited number of used images and different observation periods (CSK, 17 images from March 2016 to April 2017, and TSX, 20 images from August 2015 and October 2016). As indicated by the displacement maps, Tiexi district was subsiding rapidly during 2015-2017. According to geological data, sediments of this area are composed of interbedding gravel and fine-grained sand, which have strong water permeability, and therefore, it is prone to ground subsidence. 

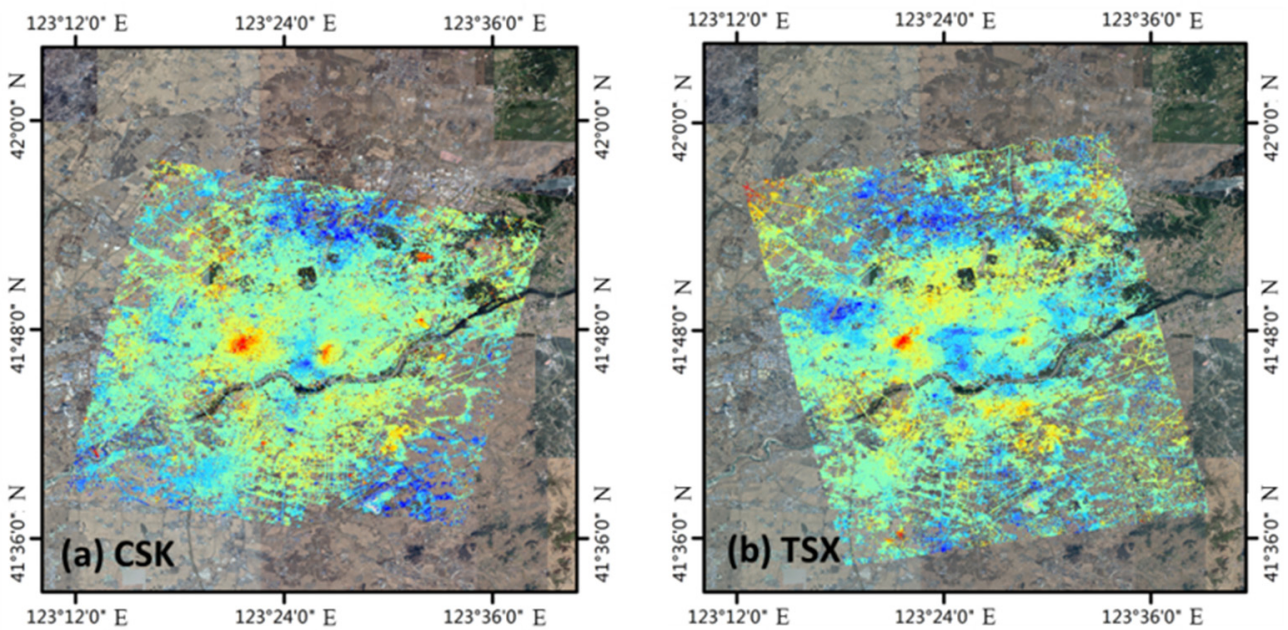

Figure 12. Mean ground velocity maps over Shenyang: (a) CSK data and (b) TerraSAR-X (TSX) data.

Displacement velocity measurements have been extracted and superimposed on subway lines, as well as the subsidence profiles along several subway tracks. To reveal the subsidence caused by subway tunnels, pixels from building facades are carefully removed according to their 3D positions. As shown in Figure 12, results from CSK and TSX are generally in good agreement. The intersection of line 1 and line 9 (Figure 13) presents severe subsidence phenomena in both the retrieved results. Actually, two sudden collapse events at the subway stations have been reported in history: one on 30 June 2016 at the intersection of line 1 and 9 and the other on 19 October 2016 at Caozhong station (marked by a red triangle in Figure 13a, as shown in Figure 14). According to the subsidence profiles in Figure 13c-f, subway stations marked with ellipsoids are detected to be subsiding by both CSK and TSX.

The displacement time series of two nearby points at Nujiang park station (marked by yellow triangle in Figure 13a) are compared with levelling data, as shown in Figure 15. The levelling data was collected during shield construction of line 9 subway tunnels, with the tunnelling pushing forward. The levelling work generally started before tunnelling and lasted until the completion of shield construction. As given by the levelling profiles of P1 and P2, there was not much ground subsidence before shield construction, and then the ground suddenly subsided during shield construction. However, after the completion of shield construction, the subsidence generally slowed down and stabilized. The MTInSAR result was able to detect the acceleration of ground subsidence during shield construction. However, it underestimated the cumulative displacement value since the SBAS method is applied. The SBAS is a distributed scatterers interferometry technique that averages backscattered signals from nearby points. Therefore, the phase jump caused by fast movement of ground target cannot be captured by SBAS. 


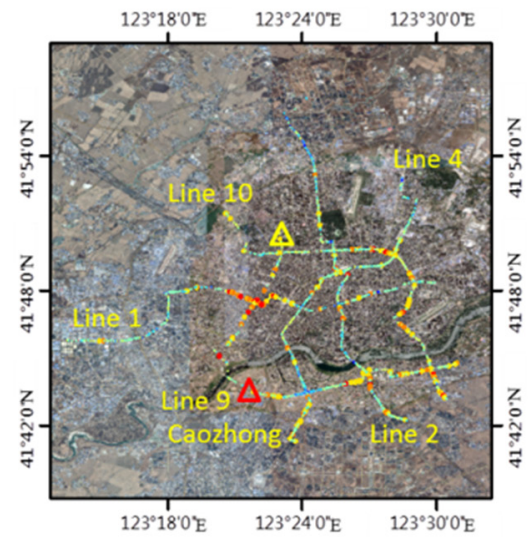

(a)

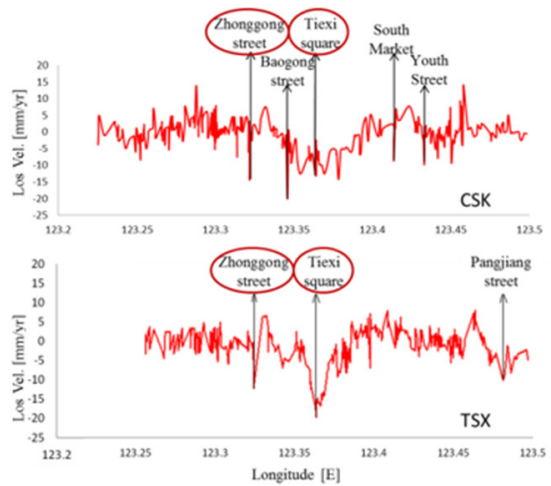

(c)

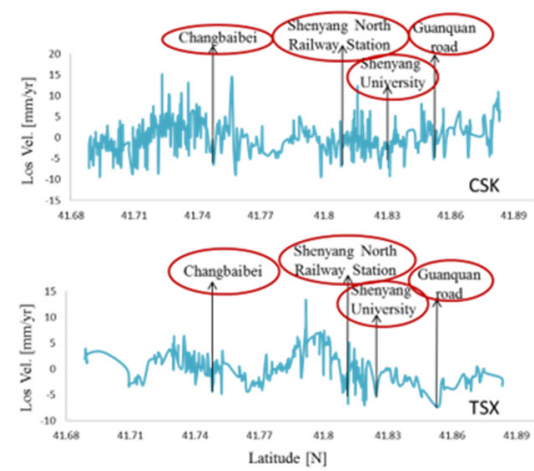

(e)

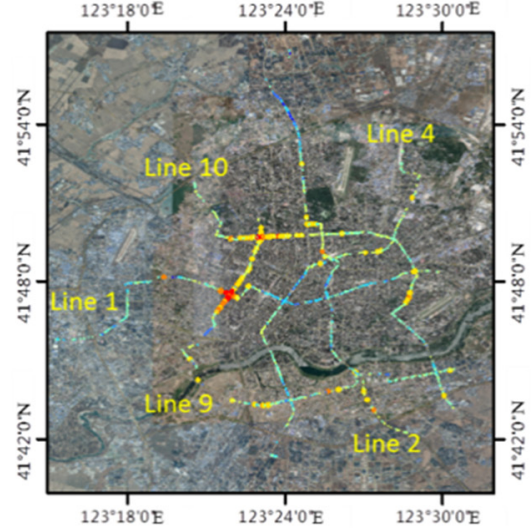

(b)

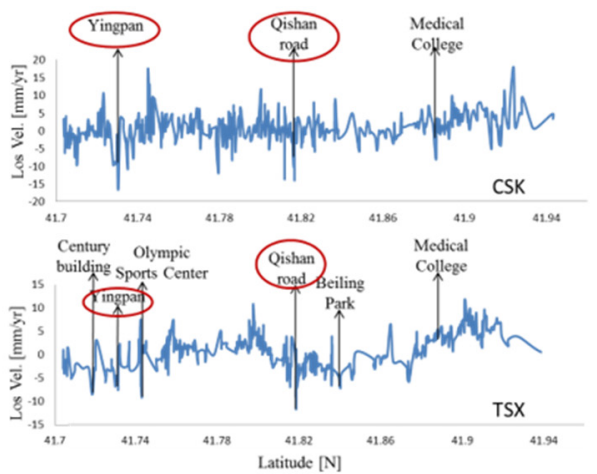

(d)

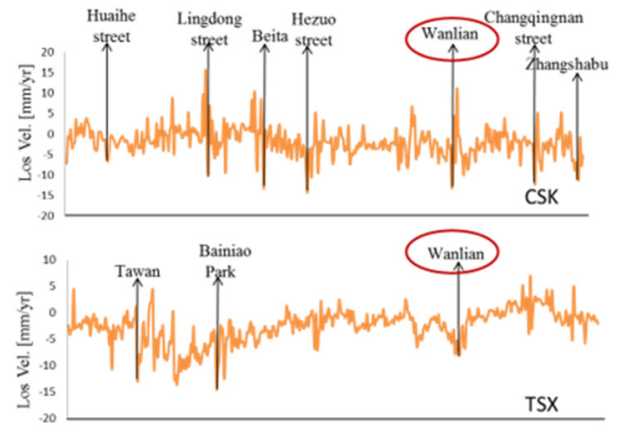

(f)

Figure 13. Comparison of displacement velocity profiles from (a) CSK and (b) TSK and analysis with respect to subway tunnels: profile along lines (c) 1, (d) 2 , (e) 4 , and (f) 10 . 


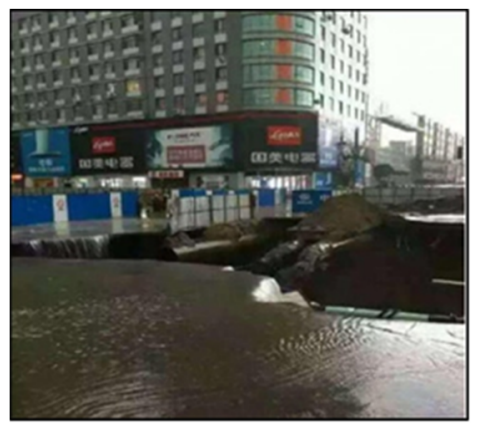

(a)

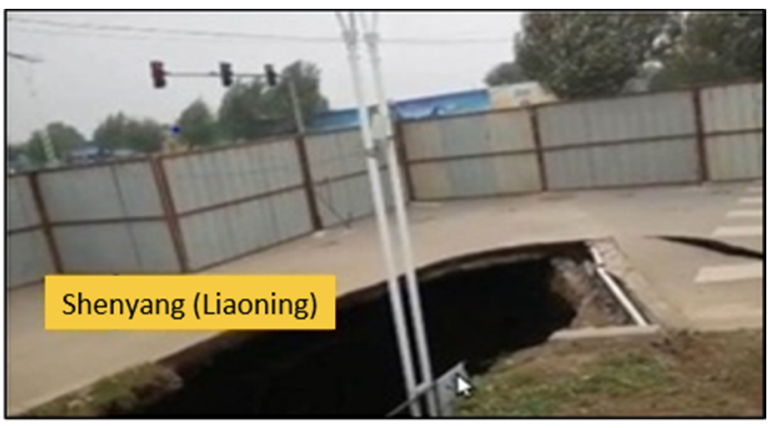

(b)

Figure 14. Images of reported collapse events along subway lines: (a) collapse at the intersection of line 1 and line 9; (b) collapse at Caozhong station (marked by red triangle in Figure 13a), line 9.

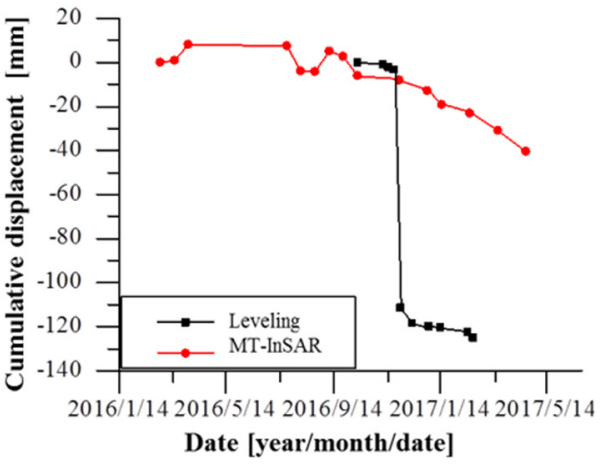

(a)

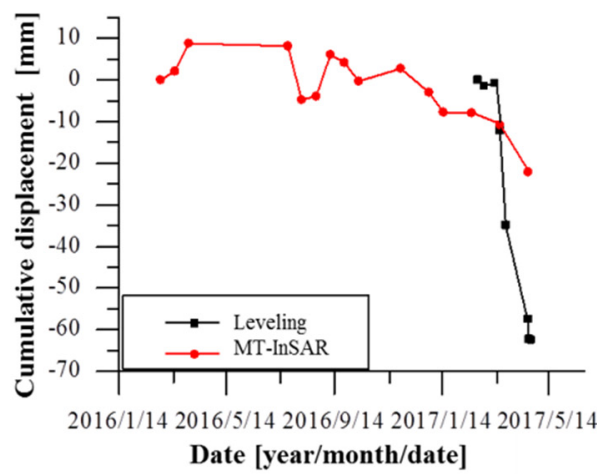

(b)

Figure 15. Comparison between MT-InSAR results from CSK and Levelling data: (a) P1; (b) P2.

\section{Discussion and Conclusions}

This paper's main purpose is to assess advanced and multi-source EO techniquesmainly MT-InSAR — applied to different areas and contexts, particularly monitoring glaciers, landslides deformations and subsidence, as well as studying potential associations between multiple geohazards and their causing factors. Each application area had a representative part of the heterogeneous Chinese territory selected as a case study.

The Yiga Glacier (Figure 2b) -more specifically, the spatial distribution of its surface velocities-was chosen to be monitored in this study. Results show that the change of velocity over time is closely related to the glacier's material balance and climate change. Indeed, considering the average state at the long run, glacial velocity depends on both climate and topographic conditions [28]. Seeing that topographic conditions do not modify significantly within short/medium time periods, changes on glacier's surface velocity are mainly affected by climate factors and through the impact that these have on the glacier's mass balance, temperature state and hydraulic characteristics [84]. An analysis correlating the Yiga Glacier' surface velocity with local average daily temperature and number of rainfall days and of snowfall days-data obtained from http:/ /lishi.tianqi.com (accessed on 20 June 2018) —was carried out and is presented in Figure 16. 


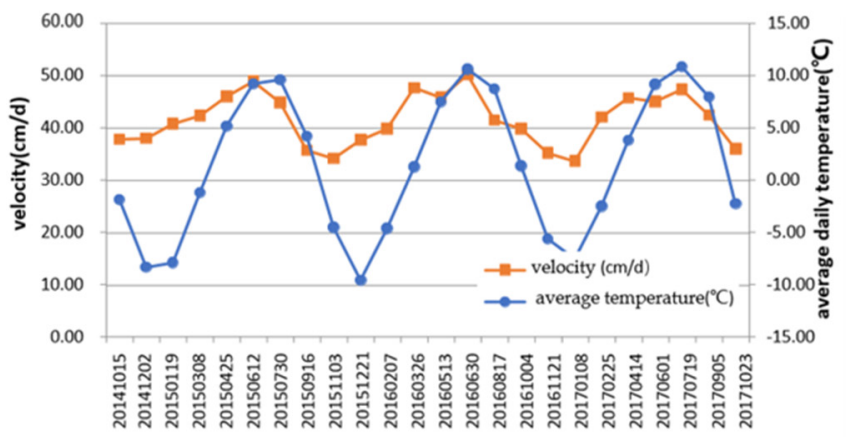

(a)

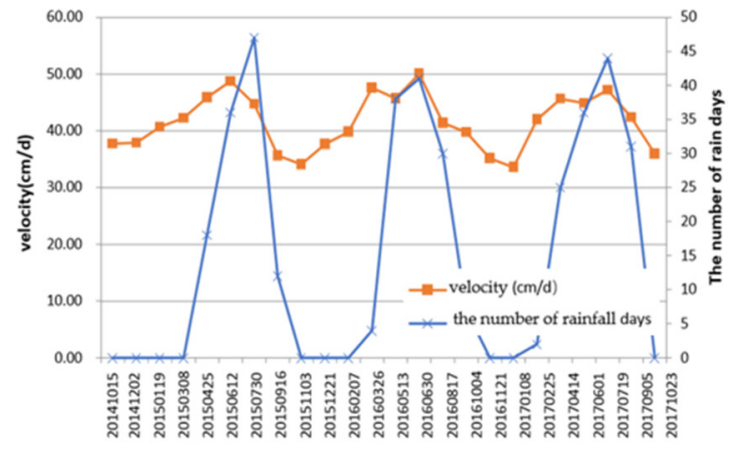

(b)

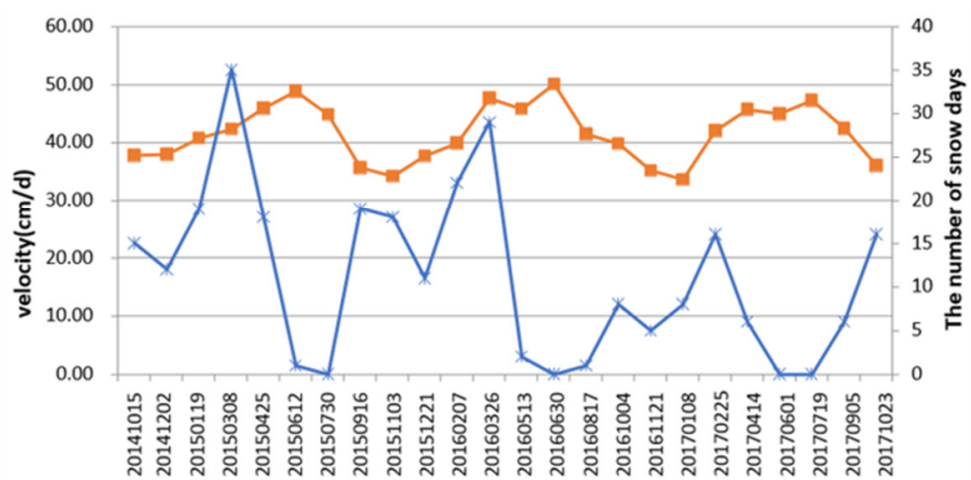

(c)

Figure 16. Average of surface velocity of the Yiga Glacier and the variation of (a) the average daily temperature, (b) the number of rainfall days, and (c) the number of snowfall days in the region over each period of the image pairs.

While Figure 16a clearly shows that the surface's velocity varies directly with the average temperature (e.g., it is greater when the average temperature is higher), the same happens with rainfall (e.g., more rainfall days mean an increase in velocity), as it can be seen in Figure 16b. Air temperature and rainfall influence on glacial velocity can be attributed to the appearance of glacial melt water, changes in sub-glacial drainage system and in the pressure at a glacier's bottom [28]. Data shows that glacial velocity reaches its maximum in the summertime. Moreover, velocity in the winter-from December to February-in the first two years is higher than that in the fall (September to November). Figure 16c shows that the number of snowfall days in the winter has increased significantly, when compared with the autumn. This also increases glacier material accumulation. Although temperature in the winter is generally lower than in the autumn, glacier material accumulation has a greater contribution to velocity, making it higher than in autumn. In 2016, fewer snowfall days in the winter led to the contrary outcome. These results are consistent with previous research [57]. Time-series velocity distributions of the Yiga Glacier were revealed for the first time by Sentinel-1 images. In addition to this specific study, and still within the scope of this project, with the assistance of a terrestrial laser scanner, the offset tracking technique based on high-resolution satellite SAR data was used to provide reliable and detailed information for local and even single glacial surface displacement monitoring in the Himalayas North Slope glacier area [57]. Based on high-precision DEM and multi-angle high-resolution COSMO images, the three-dimensional deformation inversion of a single glacier was realized. Based on these conclusions-where it was proven that the offset tracking technique is very effective in monitoring glacial flow velocity-advanced EO techniques can be considered very reliable to provide an effective remote monitoring tool for glaciers.

Regarding subsidence monitoring, the change detection results were compared visually and quantitatively (e.g., confusion matrix, AUROC) with landslide features that 
were manually delineated by a trained expert. The results achieved around Beijing confirm that the Sentinel-1 TOPS IW mode is suitable for large-scale land subsidence monitoring. Indeed, with a swath size of $250 \mathrm{~km}$ at $5 \mathrm{~m}$ by $20 \mathrm{~m}$ spatial resolution and about five times better temporal resolution than the previous C-band ERS and ENVISAT ASAR data, it is an important SAR data source for future land subsidence monitoring. Moreover, it will be further improved after the launch of Sentinel-1 C and D, bringing new opportunities for earth deformation monitoring. The presented results show clear and strong ground deformation effects, with high potential impact on the local infrastructures and population, caused by water pumping. The use of InSAR data allows us to study these phenomena with an accuracy and a temporal sampling not possible otherwise.

The very particular characteristics of the Chinese territory, similar to other mountainous regions, restrict the ability to compile landslide inventories and to keep them up to date because, in most cases, data sources (e.g., aerial photographs, satellite images, groundbased observations) are not available, which hinders an effective use within landslide risk management. Within this work, change detection techniques based on freely available and commercial optical satellite images were confronted for mapping debris slide and flow phenomena. The area located in the southeast of Gansu Province in northwest China, one of the four most serious landslide- and debris flow-prone regions in China, was selected, and it was possible to achieve the following main results: (i) the creation and updating of event-based landslide inventory maps, (ii) elaboration of the efficiency of freely available Sentinel-2 data in a change detection framework compared to higher resolution commercial data, and (3) elaboration of advantages and pitfalls of unsupervised change detection in a human-influenced landscape compared to a supervised approach that has shown that analyses based on higher resolution sensors improve the detectability of smaller landslide features and a better delineation of landslide boundaries. However, for the general creation of landslide event maps, freely available Sentinel-2 data proved to be of high utility. In the human-influenced landscape, the landslide mapping approach based on unsupervised change detection reached its limits due to omnipresent vegetation disturbance that was not related to landsliding but to vegetation changes caused by human activity or seasonal effects. Moreover, this work also highlighted the utmost importance of an additional context-driven interpretation of EO-based landslide recognition results (e.g., plausibility checks, pseudo-change identification) to identify the explanatory power of the resulting maps. Results achieved highlight that a higher spatial resolution of satellite-data goes hand in hand with a better detectability of smaller landslide features and a more accurate delineation of landslide boundaries. However, in case less detailed overview maps are required (e.g., rapid mapping of larger landslides), approaches based on freely available Sentinel-2 data still perform sufficiently well. As expected, the supervised approach outperformed the automatic thresholding procedure. Nevertheless, automatic change detection procedures are still of value in the field of landslide recognition in cases where the area of interest is rather unaffected by vegetation disturbance that can be traced to human activity (e.g., land cover change, deforestation) or seasonal effects. Ultimately, this research also showed that, despite the numerous possibilities that remote sensing and data-driven models currently offer, it remains the researcher's duty to assign the true value and application possibilities of ensuing results.

Overall, the results revealed that the further usability of landslide inventory data based on change detection critically depends on the resolution of the underlying satellite data and the purpose of the subsequent analysis. In this context, freely available Sentinel-2 data have shown to be of high utility in case maps of larger slope instabilities are needed, even for remote terrain. The results, therefore, fulfil the requirement of various first responders after high-magnitude landslide events. Yet, for smaller landslides and a detailed delineation of specific landslide features, we recommend using sensors with higher spatial resolution. In case the results are used as an input for consequent analyses (e.g., susceptibility or hazard modelling, which rely on more detailed landslide data), limitations of an automatic 
approach have to be kept in mind, such as the possibility of obtaining false positives due to human-induced land cover change or deforestation.

Finally, a traditional heavy industrial region located in northeast China (BASF area) covering more than $3000 \mathrm{~km}^{2}$ was also studied. BASF socio, economical and historical contexts deem that continuous and precise monitoring of the spatial and temporal variations of multiple geohazards in this area is important for both early warning and risk assessment. Results presented in this study show clear and strong ground deformation effects, with high potential impact on the local infrastructures and population, caused by heavy industrial exploitation of mines and water pumping in the BASF region. The use of InSAR data allows us to study these phenomena with an accuracy and a temporal sampling not possible otherwise. The MT-InSAR analyses, together with field surveys and data from different methodologies, allowed the monitoring of ground displacement with unprecedented accuracy and temporal sampling, thanks to the use of different sensors operating in various frequency band.

Establishing relations between the various geohazards may be of value for all traditional industrial regions worldwide. Furthermore, it can provide a deeper understanding of various geological disasters and help in preventing disaster and reducing damages.

\section{Future Work}

Results and analyses obtained from this work have shown the advantages of satellitebased remote sensing techniques in monitoring multi-hazards. Their continuous monitoringnamely large landslides-is key to minimize and prevent actual and future risks. Earth observation based-methods, especially MT-InSAR and change detection methods, have proven effective and valuable in the geohazards monitoring and risk assessment analysis of urban subsidence phenomena, mountain landslides, open-pit mines and glaciers, based on multi-temporal radar and optical images. In this study, the results obtained by processing data acquired by different radar sensors have shown the potential of these EO techniques and highlighted the key points for an operational use of this technology, namely: (i) temporal resolution improved by regular acquisition over large areas; (ii) use of advanced processing algorithms, able to estimate and remove most atmospheric disturbances; and (iii) significant improvements in processing power, allowing a regular update of the information over large areas. Future work will seek to continue monitoring activities mainly by means of multi-source EO data at strategic areas located in different countries. Moreover, the monitoring of structures (e.g., of strategic importance—dams and bridges—or of great heritage and historical value) more quickly and effectively is also being considered, as these structures are continuously subject to deformations caused by internal and external factors, especially when located in high-risk areas. The availability of SAR data with spatial and temporal resolutions at an unprecedented level allows us to consider the development of active systems for structural risk detecting and alerting. However, the huge amount of data that will be generated will only be possible through the use of Artificial Intelligence (AI) techniques.

The results of this project gave rise to two new projects that were supported by the fifth edition of the Dragon program. We intend to use the recent advances in EO-based processing algorithms, the advent of cloud computing and the launch of new satellite platforms, specifically designed for InSAR and optical analyses, to improve geohazards and risk assessment monitoring. The challenge for the future is to pass from the historical analysis to a near-real-time monitoring program, providing the final users and decision makers with an operational monitoring/alert system.

Author Contributions: Conceptualization, J.J.S. and J.F.; methodology, G.L., Z.P., S.S. (Stefan Steger), S.B., L.W. (Lianhuan Wei), S.Y. and S.S. (Stefano Salvi); data curation, Q.W., J.T., L.T., P.M., R.S., S.L., Y.M., C.T., C.B., S.A., G.P. and L.W. (Lixin Wu); validation, Q.W., J.T., L.T., P.M., R.S., S.L., Y.M., C.T., C.B., S.A., G.P. and L.W. (Lixin Wu); formal analysis, G.L., Z.P., S.S. (Stefan Steger), S.B., L.W. (Lianhuan Wei), E.P. and S.S. (Stefano Salvi); investigation, G.L., Z.P., S.S. (Stefan Steger), S.B., L.W. (Lianhuan Wei), S.S. (Stefano Salvi), Q.W., J.T., L.T., P.M., R.S., S.L., Y.M., C.T., C.B., S.A., G.P. and 
L.W. (Lixin Wu); resources, G.L., Z.P., S.S. (Stefan Steger), S.B., L.W. (Lianhuan Wei) and S.S. (Stefano Salvi); writing—original draft preparation, J.J.S.; writing—review and editing, J.J.S., J.F., E.P., G.L., Z.P., S.S. (Stefan Steger), S.B., L.W. (Lianhuan Wei) and S.S. (Stefano Salvi); visualization, J.J.S., E.P, J.F..; supervision, J.J.S. and J.F.; project administration, J.J.S. and J.F.; funding acquisition, G.L., J.F., Z.P., S.S. (Stefan Steger), S.B., L.W. (Lianhuan Wei) and S.S. (Stefano Salvi). All authors have read and agreed to the published version of the manuscript.

Funding: This research was funded by the Strategic Priority Research Program of the Chinese Academy of Sciences [grant number XDA19070202], the China Geological Survey [grant number DD20160342, DD20190515], the Key Research Program of Frontier Sciences, CAS [grant number QYZDY-SSW-DQC026], the National Natural Science Foundation of China (NSFC) [grant number 41590852, 41001264] and the National Science and Technology Major Project [grant number 2016ZX05054013], and the APC was funded by [XDA19070202].

Institutional Review Board Statement: Not applicable.

Informed Consent Statement: Not applicable.

Data Availability Statement: All satellite images used in this study were provided by ESA-MOST China in the scope of the Dragon 4 cooperation programme.

Acknowledgments: This research was supported by the China MOST-ESA Dragon Project-4 [grant number 32365]. All data used in this work were provided by ESA, MOST or ESA Third-Party Missions agreements. (The ALOS-2 PALSAR-2 and ALOS-1 PALSAR data are supported by JAXA RA6 project (3393); the COSMO-SkyMed data are provided by ASI via the ASI-ESA Dragon 4, the TerraSAR data are provided by DLR via the ASI-ESA Dragon 4; and the GF-3 SAR data are provided by National Satellite Marine Applications Centre.)

Conflicts of Interest: The authors declare no conflict of interest.

\section{References}

1. Yue, H.; Liu, G.; Guo, H.; Li, X.; Kang, Z.; Wang, R.; Zhong, X. Coal mining induced land subsidence monitoring using multiband spaceborne differential interferometric synthetic aperture radar data. J. Appl. Remote. Sens. 2011, 5, 053518. [CrossRef]

2. Kampes, B.; Hanssen, F.; Swart, R. Deformation Monitoring with Radar Interferometry, Analysis of Permanent Scatterers in Tianjin, China 2001, VMSG Symposium, Utrecht, The Netherlands. 19 November 2001. Available online: http:/ / doris.tudelft.nl/ Literature/kampes01a.gif (accessed on 19 October 2021).

3. Liao, M.; Tang, J.; Wang, T.; Balz, T.; Zhang, L. Landslide monitoring with high-resolution SAR data in the Three Gorges region. Sci. China Earth Sci. 2012, 55, 590-601. [CrossRef]

4. Liu, G.; Guo, H.; Perski, Z.; Fan, J.; Bai, S.; Yan, S.; Song, R. Monitoring the slope movement of the Shuping landslide in the Three Gorges Reservoir of China, using X-band time series SAR interferometry. Adv. Space Res. 2016, 57, 2487-2495. [CrossRef]

5. Fan, H.; Deng, K.; Zhu, C.; Xue, J. Monitoring land subsidence by PS-DInSAR and SBAS methods in Tianjin City. In Proceedings of the International Symposium on Lidar and Radar Mapping 2011, Nanjing, China, 26-29 May 2011; Technologies and Applications. Li, J., Ed.; SPIE: Bellingham, WA, USA, 2011; Volume 8286, pp. 409-415.

6. Perissin, D.; Wang, T. Time-Series InSAR Applications Over Urban Areas in China. IEEE J. Sel. Top. Appl. Earth Obs. Remote. Sens. 2011, 4, 92-100. [CrossRef]

7. Liu, P.; Li, Z.; Hoey, T.; Kincal, C.; Zhang, J.; Zeng, Q.; Muller, J.-P. Using advanced InSAR time series techniques to monitor landslide movements in Badong of the Three Gorges region, China. Int. J. Appl. Earth Obs. Geoinf. 2013, 21, 253-264. [CrossRef]

8. Gili, J.A.; Corominas, J.; Rius, J. Using Global Positioning System techniques in landslide monitoring. Eng. Geol. 2000, 55, 167-192. [CrossRef]

9. Calcaterra, S.; Cesi, C.; Di Maio, C.; Gambino, P.; Merli, K.; Vallario, M.; Vassallo, R. Surface displacements of two landslides evaluated by GPS and inclinometer systems: A case study in Southern Apennines, Italy. Nat. Hazards 2012, 61, 257-266. [CrossRef]

10. Nakagawa, H.; Murakami, M.; Fujiwara, S.; Tobita, M. Land subsidence of the northern Kanto plains caused by ground water extraction detected by JERS-1 SAR interferometry. In Proceedings of the IEEE 2000 International Geoscience and Remote Sensing Symposium. Taking the Pulse of the Planet: The Role of Remote Sensing in Managing the Environment. Proceedings (Cat. No.00CH37120), Honolulu, HI, USA, 24-28 July 2000; Volume 5, pp. 2233-2235.

11. Khan, S.A.; Liu, L.; Wahr, J.; Howat, I.; Joughin, I.; van Dam, T.; Fleming, K. GPS measurements of crustal uplift near Jakobshavn Isbræ due to glacial ice mass loss. J. Geophys. Res: Solid Earth 2010, 115, B09405. [CrossRef]

12. Ferretti, A.; Prati, C.; Rocca, F. Permanent scatterers in SAR interferometry. IEEE Trans. Geosci. Remote. Sens. 2001, 39, 8-20. [CrossRef]

13. Adam, N.; Kampes, B.; Eineder, M. Development of a scientific permanent scatterer system: Modifications for mixed ERS/ENVISAT time series. In Proceedings of the Envisat Symposium 2004, Salzburg, Austria, 6-10 September 2004. 
14. Hilley, G.E.; Bürgmann, R.; Ferretti, A.; Novali, F.; Rocca, F. Dynamics of slow-moving landslides from permanent scatterer analysis. Science 2004, 304, 1952-1955. [CrossRef] [PubMed]

15. Wasowski, J.; Bovenga, F. Investigating landslides and unstable slopes with satellite Multi Temporal Interferometry: Current issues and future perspectives. Eng. Geol. 2014, 174, 103-138. [CrossRef]

16. Ferretti, A.; Prati, C.; Rocca, F. Analysis of permanent scatterers in SAR interferometry. In Proceedings of the IEEE 2000 International Geoscience and Remote Sensing Symposium. Taking the Pulse of the Planet: The Role of Remote Sensing in Managing the Environment. Proceedings (Cat. No.00CH37120), Honolulu, HI, USA, 24-28 July 2000; Volume 2, pp. 761-763.

17. De Luca, C.; Bonano, M.; Casu, F.; Fusco, A.; Lanari, R.; Manunta, M.; Manzo, M.; Pepe, A.; Zinno, I. Automatic and systematic Sentinel-1 SBAS-DInSAR processing chain for deformation time-series generation. Procedia Comput. Sci. 2016, 100, 1176-1180. [CrossRef]

18. Ferretti, A.; Fumagalli, A.; Novali, F.; Prati, C.; Rocca, F.; Rucci, A. A new algorithm for processing interferometric data-stacks: SqueeSAR. IEEE Trans. Geosci. Remote. Sens. 2011, 49, 3460-3470. [CrossRef]

19. Zhao, C.; Lu, Z.; Zhang, Q.; de La Fuente, J. Large-area landslide detection and monitoring with ALOS/PALSAR imagery data over Northern California and Southern Oregon, USA. Remote. Sens. Environ. 2012, 124, 348-359. [CrossRef]

20. Yan, S.; Guo, H.; Liu, G.; Ruan, Z. Mountain glacier displacement estimation using a DEM-assisted offset tracking method with ALOS/PALSAR data. Remote. Sens. Lett. 2013, 4, 494-503. [CrossRef]

21. Yan, S.; Liu, G.; Deng, K.; Wang, Y.; Zhang, S.; Zhao, F. Large deformation monitoring over a coal mining region using pixel-tracking method with high-resolution Radarsat-2 imagery. Remote. Sens. Lett. 2016, 7, 219-228. [CrossRef]

22. Guo, H.; Liu, G.; Liao, J.; Li, X.; Zhang, L.; Shen, G.; Fu, W.; Sun, Z. Study of RADARSAT-2 synthetic aperture radar data for observing sensitive factors of global environmental change. J. Appl. Remote. Sens. 2014, 8, 084593. [CrossRef]

23. Liu, G.; Guo, H.; Yue, H.; Perski, Z.; Yan, S.; Song, R.; Fan, J.; Ruan, Z. Modified four-pass differential SAR interferometry for estimating mountain glacier surface velocity fields. Remote. Sens. Lett. 2016, 7, 1-10. [CrossRef]

24. Novellino, A.; Cigna, F.; Sowter, A.; Ramondini, M.; Calcaterra, D. Exploitation of the Intermittent SBAS (ISBAS) algorithm with COSMO-SkyMed data for landslide inventory mapping in north-western Sicily, Italy. Geomorphology 2017, 280, 153-166. [CrossRef]

25. Dong, J.; Zhang, L.; Tang, M.; Liao, M.; Xu, Q.; Gong, J.; Ao, M. Mapping landslide surface displacements with time series SAR interferometry by combining persistent and distributed scatterers: A case study of Jiaju landslide in Danba, China. Remote. Sens. Environ. 2018, 205, 180-198. [CrossRef]

26. Zhang, Y.; Meng, X.; Jordan, C.; Novellino, A.; Dijkstra, T.; Chen, G. Investigating slow-moving landslides in the Zhouqu region of China using InSAR time series. Landslides 2018, 15, 1299-1315. [CrossRef]

27. Joughin, I. Ice-sheet velocity mapping: A combined interferometric and speckle-tracking approach. Ann. Glaciol. 2002, 34, 195-201. [CrossRef]

28. Xie, Z.; Liu, C. Introduction to glaciology; Shanghai Popular Science Press: Shanghai, China, 2010.

29. Bolch, T.; Buchroithner, M.F.; Peters, J.; Baessler, M.; Bajracharya, S. Identification of glacier motion and potentially dangerous glacial lakes in the Mt. Everest region/Nepal using spaceborne imagery. Nat. Hazards Earth Syst. Sci. 2008, 8, 1329-1340. [CrossRef]

30. Herman, F.; Anderson, B.; Leprince, S. Mountain glacier velocity variation during a retreat/advance cycle quantified using sub-pixel analysis of ASTER images. J. Glaciol. 2011, 57, 197-207. [CrossRef]

31. Guerriero, L.; Di Martire, D.; Calcaterra, D.; Francioni, M. Digital image correlation of Google Earth images for Earth's surface displacement estimation. Remote. Sens. 2020, 12, 3518. [CrossRef]

32. Yao, X.; Liu, S.; Sun, M.; Zhang, X. Study on the glacial lake outburst flood events in Tibet since the 20th century. Ziran Ziyuan Xuebao 2014, 29, 1377-1390.

33. Mouginot, J.; Scheuchl, B.; Rignot, E. Mapping of ice motion in Antarctica using synthetic-aperture radar data. Remote. Sens. 2012, 4, 2753-2767. [CrossRef]

34. Mouginot, J.; Rignot, E. Ice motion of the Patagonian icefields of South America: 1984-2014. Geophys. Res. Lett. 2015, 42, 1441-1449. [CrossRef]

35. Gudmundsson, S.; Gudmundsson, M.T.; Björnsson, H.; Sigmundsson, F.; Rott, H.; Carstensen, J.M. Three-dimensional glacier surface motion maps at the Gjálp eruption site, Iceland, inferred from combining InSAR and other ice-displacement data. Ann. Glaciol. 2002, 34, 315-322. [CrossRef]

36. Short, N.; Gray, A. Glacier dynamics in the Canadian High Arctic from RADARSAT-1 speckle tracking. Can. J. Remote. Sens. 2005, 31, 225-239. [CrossRef]

37. Schneevoigt, N.J.; Sund, M.; Bogren, W.; Kääb, A.; Weydahl, D.J. Glacier displacement on Comfortlessbreen, Svalbard, using 2-pass differential SAR interferometry (DInSAR) with a digital elevation model. Polar Rec. 2012, 48, 17-25. [CrossRef]

38. Joughin, I.; Kwok, R.; Fahnestock, M. Estimation of ice-sheet motion using satellite radar interferometry: Method and error analysis with application to Humboldt Glacier, Greenland. J. Glaciol. 1996, 42, 564-575. [CrossRef]

39. Gray, A.L.; Mattar, K.E.; Vachon, P.W.; Bindschadler, R.; Jezek, K.C.; Forster, R.; Crawford, J.P. InSAR results from the RADARSAT Antarctic Mapping Mission data: Estimation of glacier motion using a simple registration procedure. In Proceedings of the 1998 IEEE International Geoscience and Remote Sensing; IEEE, Seattle, WA, USA, 6-10 July 1998; Volume 3, pp. $1638-1640$. 
40. Bechor, N.B.; Zebker, H.A. Measuring two-dimensional movements using a single InSAR pair. Geophys. Res. Lett. $2006,33$. [CrossRef]

41. Covello, F.; Battazza, F.; Coletta, A.; Lopinto, E.; Fiorentino, C.; Pietranera, L.; Valentini, G.; Zoffoli, S. COSMO-SkyMed an existing opportunity for observing the Earth. J. Geodyn. 2010, 49, 171-180. [CrossRef]

42. Carturan, L.; Blasone, G.; Calligaro, S.; Carton, A.; Cazorzi, F.; Dalla Fontana, G.; Moro, D. High-resolution monitoring of current rapid transformations on glacial and periglacial environments. Int. Arch. Photogramm. Remote. Sens. Spat. Inf. Sci. 2013, 5, W3. [CrossRef]

43. Telling, J.; Lyda, A.; Hartzell, P.; Glennie, C. Review of Earth science research using terrestrial laser scanning. Earth Sci. Rev. 2017, 169, 35-68. [CrossRef]

44. Liu, Y.; Qu, Y.; Lei, Z.; Wang, W. Multi-sector reduction potential of embodied carbon emissions in China: A case study of Liaoning province. Environ. Dev. Sustain. 2020, 22, 5585-5602. [CrossRef]

45. Wang, J.; Zhao, F.; Yang, J.; Li, X. Mining site reclamation planning based on land suitability analysis and ecosystem services evaluation: A case study in Liaoning province, China. Sustainability 2017, 9, 890. [CrossRef]

46. Qin, Y.; Lu, P.; Li, Z. LANDSLIDE INVENTORY MAPPING FROM BITEMPORAL 10 m SENTINEL-2 IMAGES USING CHANGE DETECTION BASED MARKOV RANDOM FIELD. Int. Arch. Photogramm. Remote. Sens. Spat. Inf. Sci. 2018, Volume XLII-3, 42. [CrossRef]

47. Guzzetti, F.; Mondini, A.C.; Cardinali, M.; Fiorucci, F.; Santangelo, M.; Chang, K.-T. Landslide inventory maps: New tools for an old problem. Earth Sci. Rev. 2012, 112, 42-66. [CrossRef]

48. Van Westen, C.J.; Castellanos, E.; Kuriakose, S.L. Spatial data for landslide susceptibility, hazard, and vulnerability assessment: An overview. Eng. Geol. 2008, 102, 112-131. [CrossRef]

49. Jaboyedoff, M.; Abellán, A.; Carrea, D.; Derron, M.-H.; Matasci, B.; Michoud, C. Mapping and monitoring of landslides using LiDAR. In Natural Hazards; CRC Press: Boca Raton, FL, USA, 2018; pp. 397-420, ISBN 1-315-16684-4.

50. Scaioni, M.; Longoni, L.; Melillo, V.; Papini, M. Remote sensing for landslide investigations: An overview of recent achievements and perspectives. Remote. Sens. 2014, 6, 9600-9652. [CrossRef]

51. Ramos-Bernal, R.N.; Vázquez-Jiménez, R.; Romero-Calcerrada, R.; Arrogante-Funes, P.; Novillo, C.J. Evaluation of unsupervised change detection methods applied to landslide inventory mapping using ASTER imagery. Remote. Sens. 2018, 10, 1987. [CrossRef]

52. Mondini, A.C.; Chang, K.-T.; Yin, H.-Y. Combining multiple change detection indices for mapping landslides triggered by typhoons. Geomorphology 2011, 134, 440-451. [CrossRef]

53. Lu, P.; Qin, Y.; Li, Z.; Mondini, A.C.; Casagli, N. Landslide mapping from multi-sensor data through improved change detectionbased Markov random field. Remote. Sens. Environ. 2019, 231, 111235. [CrossRef]

54. Amatya, P.; Kirschbaum, D.; Stanley, T. Use of very high-resolution optical data for landslide mapping and susceptibility analysis along the Karnali highway, Nepal. Remote. Sens. 2019, 11, 2284. [CrossRef]

55. Hölbling, D.; Eisank, C.; Albrecht, F.; Vecchiotti, F.; Friedl, B.; Weinke, E.; Kociu, A. Comparing manual and semi-automated landslide mapping based on optical satellite images from different sensors. Geosciences 2017, 7, 37. [CrossRef]

56. Planet Application Program Interface: In Space for Life on Earth. Available online: https://api.planet.com (accessed on 1 September 2021).

57. Fan, J.; Wang, Q.; Liu, G.; Zhang, L.; Guo, Z.; Tong, L.; Peng, J.; Yuan, W.; Zhou, W.; Yan, J.; et al. Monitoring and analyzing mountain glacier surface movement using SAR data and a terrestrial laser scanner: A case study of the Himalayas North Slope Glacier Area. Remote. Sens. 2019, 11, 625. [CrossRef]

58. Strozzi, T.; Luckman, A.; Murray, T.; Wegmuller, U.; Werner, C.L. Glacier motion estimation using SAR offset-tracking procedures. IEEE Trans. Geosci. Remote. Sens. 2002, 40, 2384-2391. [CrossRef]

59. Jiang, Z.; Liu, S.; Peters, J.; Lin, J.; Long, S.; Han, Y.; Wang, X. Analyzing Yengisogat Glacier surface velocities with ALOS PALSAR data feature tracking, Karakoram, China. Environ. Earth Sci. 2012, 67, 1033-1043. [CrossRef]

60. Schellenberger, T.; Dunse, T.; Kääb, A.; Kohler, J.; Reijmer, C. Surface speed and frontal ablation of Kronebreen and Kongsbreen, NW Svalbard, from SAR offset tracking. Cryosphere 2015, 9, 2339-2355. [CrossRef]

61. Yan, S.; Ruan, Z.; Liu, G.; Deng, K.; Lv, M.; Perski, Z. Deriving ice motion patterns in mountainous regions by integrating the intensity-based pixel-tracking and phase-based D-InSAR and MAI approaches: A case study of the Chongce glacier. Remote. Sens. 2016, 8, 611. [CrossRef]

62. Crosetto, M.; Monserrat, O.; Cuevas-González, M.; Devanthéry, N.; Crippa, B. Persistent scatterer interferometry: A review. ISPRS J. Photogramm. Remote. Sens. 2016, 115, 78-89. [CrossRef]

63. Rosen, P.A.; Hensley, S.; Joughin, I.R.; Li, F.K.; Madsen, S.N.; Rodriguez, E.; Goldstein, R.M. Synthetic aperture radar interferometry. Proc. IEEE 2000, 88, 333-382. [CrossRef]

64. Hooper, A.; Segall, P.; Zebker, H. Persistent scatterer interferometric synthetic aperture radar for crustal deformation analysis. J. Geophys. Res. 2007, 112, 1-21.

65. Hooper, A. A multi-temporal InSAR method incorporating both persistent scatterer and small baseline approaches. Geophys. Res. Lett. 2008, 35, L16302. [CrossRef]

66. Perski, Z.; Liu, G.; Wojciechowski, T.; Jinhui, F.; Wójcik, A. Monitoring the Activity of Landslides in the Coastal Zones of Reservoirs with SAR Interferometry. In Landslide Science for a Safer Geoenvironment; Springer: Berlin/Heidelberg, Germany, 2014; pp. 331-336. 
67. Galloway, D.L.; Hudnut, K.W.; Ingebritsen, S.; Phillips, S.P.; Peltzer, G.; Rogez, F.; Rosen, P. Detection of aquifer system compaction and land subsidence using interferometric synthetic aperture radar, Antelope Valley, Mojave Desert, California. Water Resour. Res. 1998, 34, 2573-2585. [CrossRef]

68. Amelung, F.; Jonsson, S.; Zebker, H.; Segall, P. Prospects of Volcano Geodesy with ERS Radar Interferometry. Eur. Space Agency (Special Publication) ESA SP 2000, 177-185.

69. Qi, W.; Wei, M.; Yang, W.; Xu, C.; Ma, C. Automatic mapping of landslides by the ResU-net. Remote. Sens. 2020, $12,2487$. [CrossRef]

70. Yu, B.; Chen, F.; Muhammad, S. Analysis of satellite-derived landslide at Central Nepal from 2011 to 2016. Environ. Earth Sci. 2018, 77, 1-12. [CrossRef]

71. Behling, R.; Roessner, S.; Golovko, D.; Kleinschmit, B. Derivation of long-term spatiotemporal landslide activity-A multi-sensor time series approach. Remote. Sens. Environ. 2016, 186, 88-104. [CrossRef]

72. Hengl, T. Finding the right pixel size. Comput. Geosci. 2006, 32, 1283-1298. [CrossRef]

73. Steger, S.; Schmaltz, E.; Glade, T. The (f) utility to account for pre-failure topography in data-driven landslide susceptibility modelling. Geomorphology 2020, 354, 107041. [CrossRef]

74. Fawcett, T. An introduction to ROC analysis. Pattern Recognit. Lett. 2006, 27, 861-874. [CrossRef]

75. Hosmer Jr, D.W.; Lemeshow, S.; Sturdivant, R.X. Applied logistic regression; John Wiley \& Sons: Hoboken, NJ, USA, 2013; Volume 398, ISBN 0-470-58247-2.

76. Bovolo, F.; Marchesi, S.; Bruzzone, L. A framework for automatic and unsupervised detection of multiple changes in multitemporal images. IEEE Trans. Geosci. Remote. Sens. 2011, 50, 2196-2212. [CrossRef]

77. Dempster, A.P.; Laird, N.M.; Rubin, D.B. Maximum likelihood from incomplete data via the EM algorithm. J. R. Stat. Soc. Ser. B 1977, 39, 1-22.

78. Bazi, Y.; Bruzzone, L.; Melgani, F. Image thresholding based on the EM algorithm and the generalized Gaussian distribution. Pattern Recognit 2007, 40, 619-634. [CrossRef]

79. Bruzzone, L.; Prieto, D.F. Automatic analysis of the difference image for unsupervised change detection. IEEE Trans. Geosci. Remote. Sens. 2000, 38, 1171-1182. [CrossRef]

80. Guo, W.; Liu, S.; Yao, X.; Xu, J.; Shangguan, D.; Wu, L.; Zhao, J.; Liu, Q.; Jiang, Z.; Wei, J. The Second Glacier Inventory Dataset of China; (Version 1.0): Cold and Arid Regions Science Data Center at Lanzhou: Lanzhou, China, 2014; p. 20.

81. Ng, A.H.-M.; Ge, L.; Li, X.; Zhang, K. Monitoring ground deformation in Beijing, China with persistent scatterer SAR interferometry. J. Geod. 2012, 86, 375-392. [CrossRef]

82. Guo, J.; Hu, J.; Li, B.; Zhou, L.; Wang, W. Land subsidence in Tianjin for 2015 to 2016 revealed by the analysis of Sentinel-1A with SBAS-InSAR. J. Appl. Remote. Sens. 2017, 11, 026024. [CrossRef]

83. Guang, L.; Zbigniew, P.; Stefano, S.; Benni, T.; Lixin, W.; Jinghui, F.; Shibiao, B.; Lianhuan, W.; Shiyong, Y.; Rui, S. Land Surface Displacement Geohazards Monitoring Using Multi-temporal InSAR Techniques. J. Surv. Eng. 2021, 4, 77-87.

84. Wang, X.; Liu, Q.; Jiang, L.; Liu, S.; Ding, Y.; Jiang, Z. Characteristics and influence factors of glacier surface flow velocity in the Everest region, the Himalayas derived from ALOS/PALSAR images. J. Glaciol. Geocryol 2015, 37, 570-579. 